\title{
Task-specific iconic gesturing during spoken discourse in aphasia
}

\author{
Brielle C. Stark, PhD \& Caroline Cofoid, B.A.
}

Indiana University Bloomington

Department of Speech, Language and Hearing Sciences

200 S Jordan Avenue, Bloomington IN 47405 USA

Corresponding author:

Brielle C. Stark, PhD

bcstark@iu.edu

Neither author has a conflict of interest.

There is no funding to report for this work. 


\section{Abstract}

2 Purpose: In persons living with aphasia, we will explore the relationship between iconic gesture

3 production during spontaneous speech and discourse task, spoken language, and demographic

4 information.

5 Method: Employing the AphasiaBank database, we coded iconic gestures in $\mathrm{N}=75$ speakers with

6 aphasia during two spoken discourse tasks: a procedural narrative, which involved participants

7 telling the experimenter how to make a sandwich ("Sandwich"), and a picture sequence narrative,

8 which had participants describe the picture sequence to the experimenter ("Window"). $\mathrm{N}=43$

9 produced a gesture during both tasks, and we further evaluate data from this subgroup as a more

10 direct comparison between tasks.

11 Results: More iconic gestures, at a higher rate, were produced during the procedural narrative. For

12 both tasks, there was a relationship between iconic gesture rate, modeled as iconic gestures per

13 word, and metrics of language dysfluency extracted from the discourse task, and a metric of

14 fluency extracted from a standardized battery. Iconic gesture production was correlated with

15 aphasia duration, which was driven by performance during only a single task (Window), but not

16 with other demographic metrics, such as aphasia severity or age. We also provide preliminary

17 evidence for task differences shown through the lens of two types of iconic gestures.

18 Conclusions: Whilst speech-language pathologists have utilized gesture in therapy for post-stroke

19 aphasia, due to its possible facilitatory role in spoken language, there has been considerably less

20 work in understanding how gesture differs across naturalistic tasks, and how we can best utilize

21 this information to better assess gesture in aphasia, and improve multimodal treatment for aphasia.

22 Further, our results contribute to gesture theory, in particular about the role of gesture across

23 naturalistic tasks, and its relationship with spoken language. 


\section{Introduction}

25 Gesture is a powerful tool that accompanies and, sometimes, replaces speech. Gestures lie along a 26 continuum (Kendon's Continuum; McNeil, 1992), ranging from gestures with no linguistic

27 association, to gestures associated with speech ('language-like gestures'), to gestures conveying 28 meaning in the absence of speech ('pantomimes'), and gestures holding independent status as 29 symbolic forms ('emblems,' e.g., the “OK” sign).

\section{Gesturing in Aphasia}

31 In the case of persons living with acquired aphasia - a language disorder - gesturing may serve a

32 particularly communicative purpose, as a means of compensating for spoken language difficulties

33 or, indeed, as a mechanism to overcome word finding difficulties (reminiscent of what Luria 34 termed inter-systemic reorganization (Luria, 1970) (Dipper et al., 2015; Hadar \& Butterworth, 35 1997; Krauss, 1998; Rose \& Douglas, 2001). There is emerging evidence that people with aphasia 36 use gestures to accompany/be redundant with (Kong et al., 2017) or supplement (e.g., 37 disambiguate, add) (Dipper et al., 2015) speech. The relationship between language and gesture 38 has also been explored in neurotypical populations, more often finding that gesture is redundant 39 with speech (Dargue et al., 2019; Holle \& Gunter, 2007; Hostetter, 2011; Kelly et al., 1999).

40 In this study, we focus on iconic gestures. Iconic gestures are language-like gestures which are 41 related to the content of speech and have a form (e.g., motion, hand-shape, location) that is related 42 to this content; they typically are not meaningful in the absence of speech (Hadar \& Butterworth, 43 1997). Iconic gestures are highly common in aphasia. Indeed, a study in $\mathrm{N}=95$ persons with aphasia 44 demonstrated that all subjects employed at least one type of iconic gesture during a fictional story 45 retell (Cinderella story), further emphasizing reliance on iconic gesture to convey, disambiguate, 
46 or add meaning during discourse by persons with otherwise impoverished spoken language

47 (Sekine \& Rose, 2013b).

48 Theories of Gesture's Relationship with Language in Aphasia

49 There are several theories that have been used to describe gesture use in aphasia. The Sketch model

50 suggests that, when gesturing gets harder, speakers will rely relatively more on speech, and,

51 alternatively, that when speaking gets harder, speakers will rely relatively more on gestures (de

52 Ruiter et al., 2012; de Ruiter, 2006). This theory shares similarities with Growth Point theory,

53 which postulates that gesture and language share pre-linguistic conceptual stage resources before

54 diverging - with language taking a linguistic path, and gesture a motoric one (McNeil, 1992).

55 Broadly, these theories fit with evidence comparing iconic gesture usage in aphasia to gesture

56 usage in matched samples of persons without aphasia, finding almost always that persons with

57 aphasia gesture more often whilst also producing less speech (Sekine \& Rose, 2013b). In an

58 alternative hypothesis, the Lexical Retrieval hypothesis, gestures are thought to directly facilitate

59 lexical retrieval processes (Krauss, 1998; Krauss \& Hadar, 2001). Iconic gestures, in particular,

60 are thought to originate in the processes that precede conceptualization / formulation of the

61 preverbal message, and as such can precede even in cases of blockages or damage to later stages.

62 Importantly, this theory hypothesizes that the imagistic information from iconic gesture may

63 facilitate lexical retrieval by "defining the conceptual input to the semantic lexicon; by maintaining

64 a set of core features while reselecting a lexical entry; and by means of directly activating

65 phonological word-forms" (Hadar \& Butterworth, 1997). Indeed, iconic gesturing has been shown

66 to improve object naming (Rose \& Douglas, 2001) and occur alongside word finding problems

67 (Kong et al., 2015a; Pritchard et al., 2013). 
Notably, gesture is also thought to reflect underlying thoughts and knowledge not verbalized

69 in speech (Church \& Goldin-Meadow, 1986; Goldin-Meadow \& Alibali, 2013), which allow

70 persons with aphasia to communicate and demonstrate competence despite a language production

71 barrier.

\section{The Relationship of Iconic Gesture with Spoken Language Fluency}

73 Not surprisingly, given the theories above, language dysfluency is thought to correlate with greater

74 gesture use in aphasia. Most research evaluating the relationship between language dysfluency and

75 iconic gesture in aphasia use has focused on the differing frequency of iconic gesture use stratified

76 by aphasia type. That is, a comparison of iconic gesturing in persons with non-fluent as compared

77 to fluent aphasia (a dichotomous type of fluency classification), or a comparison of iconic 78 gesturing in persons with aphasia types based on standardized testing batteries (i.e., a 79 classificationist type of fluency classification, e.g., Broca's, Conduction, Wernicke's). In general, 80 this research has been mixed, with some studies finding significantly more iconic gesture use in 81 non-fluent populations, primarily Broca’s aphasia (Goldblum, 1978; Hadar, 1991; but see, Cicone 82 et al., 1979) whilst other studies have observed a high incidence of iconic gestures across all 83 aphasia types (Feyereisen, 1983; Sekine \& Rose, 2013a).

84 Cicone et al. (1979) found that people with non-fluent aphasia produced fewer gestures (yet 85 these were clear and informative), which contrasted with the frequent gestures produced by people 86 with fluent aphasia, which were vague. In a relatively large sample of people with aphasia 87 completing a story retell task, people with Broca's aphasia (a type of non-fluent aphasia) produced 88 overall more gestures, and were more likely to produce iconic gestures (Sekine \& Rose, 2013b).

89 In a single case study of a person with conduction aphasia (a type of fluent aphasia), it was found 90 that, when recounting a cartoon, the individual with conduction aphasia produced more iconic 
91 gestures than a comparison sample of controls during word searching behavior (Pritchard et al.,

92 2013). Interestingly, this individual produced a similar frequency of iconic gestures compared with

93 control participants when the person with aphasia was producing fluent, errorless language. In a

94 larger sample of persons with aphasia and matched controls, iconic gestures were produced in

95 similar frequencies and forms by both groups, but the aphasia group utilized iconic gestures

96 alongside their otherwise semantically impoverished language (Pritchard et al., 2015). Whilst this

97 evidence seems relatively straightforward (emphasizing the use of more gestures, in particular

98 iconic type, by persons with non-fluent and/or Broca's aphasia), some studies have provided

99 alternative findings. For example, one study found that persons with Wernicke's aphasia (a fluent

100 type) produce more iconic gestures per unit of time (Carlomagno \& Cristilli, 2006).

101 Overall, it is difficult to draw conclusions based on iconic gesture frequency and rate by 102 evaluations leveraging aphasia type because of the vast intra-group differences in language ability 103 within aphasia types (Dalton \& Richardson, 2019; Stark \& Fukuyama, 2020). For example, iconic 104 gestures likely rely on some intact pre-linguistic components, such as pre-linguistic conceptual 105 knowledge (Hadar \& Butterworth, 1997). Some persons with Wernicke's aphasia can present with 106 impoverished pre-linguistic conceptual ability, whilst other persons with Wernicke's aphasia can 107 present with relatively intact pre-linguistic conceptual ability (Kertesz, 2007). This makes drawing 108 overarching conclusions about gesture usage stratified by aphasia type inherently difficult and, 109 perhaps, not meaningful.

110 Instead, evaluations of gesture use, in particular iconic gesture use, may be more sensitively 111 investigated by evaluating the relationship of gesture with metrics of language derived from the 112 task itself (e.g., dysfluencies), and with some extra-task metric of fluency that provides a category 113 or metric of fluency, as opposed to an aphasia type. Restricting gesture use in neurotypical adults 
114 has demonstrated reduced speech fluency, measured by an association of gesture use (or non-use)

115 with time spent pausing, number of words, number of pauses, mean pause length, and number of

116 hesitations (Graham \& Heywood, 1975), with relative frequency of non-juncture filled pauses in

117 speech with spatial content (Rauscher et al., 1996), and with a slower speech rate (Morsella \&

118 Krauss, 2004). A study by Kong et al. (2015) evaluated N=48 Cantonese speaking persons with

119 aphasia, comparing gesture use with several linguistic measures produced during narrative tasks,

120 including type-token ratio, percentage of simple utterances, percentage of complete utterances, and

121 percentage of dysfluency (defined as repetitions of words or syllables, sound prolongations,

122 pauses, self- corrections, and interjections, as a proportion of total utterances). Those who tended

123 to produce higher numbers of gestures were also those who demonstrated a higher proportion of

124 dysfluencies, and a lower number of complete and simple utterances. There was not a significant

125 difference between high/low gesture groups in regards to lexical diversity (type-token ratio) (Kong

126 et al., 2015). A more recent study by Kong et al. (2017) further emphasized the relationship

127 between dysfluency and gesture use in Cantonese speakers with aphasia, finding that percentages

128 of complete sentences and dysfluency strongly predicted the gesturing rate in aphasia. Both Kong

129 et al. $(2015,2017)$ and other studies evaluating language dysfluency's relationship with gesture in

130 aphasia (e.g., Sekine \& Rose, 2013b) have collapsed across gesture types, so further work

131 evaluating iconic gesture's relationship with language dysfluency in aphasia is warranted.

\section{The Role of Task in Gesture Use}

133 While the literature has made clear that iconic gestures are heavily used in aphasia, there exist

134 critical gaps. The primary gap targeted by our project is on task-specificity of iconic gesture use

135 in aphasia. Most studies evaluating iconic gesture in aphasia have focused on gesturing during a

136 single narrative task (e.g., fictional story retell) (Kistner et al., 2019; Pritchard et al., 2015; Sekine 
$137 \&$ Rose, 2013a). However, restricting evaluation of iconic gestures to a single narrative task likely

138 lends us an impoverished understanding of how, when and why iconic gestures are employed in

139 naturalistic contexts. For example, speakers (without aphasia) gesture more when a task is

140 cognitively or linguistically complex (Kita \& Davies, 2009). Indeed, evidence from participants

141 with amnesia and healthy comparison participants suggest that both subject groups gesture at lower

142 rates during procedural discourse tasks compared to autobiographical/episodic narratives, likely

143 because autobiographical/episodic narratives reflect rich episodic details (Hilverman et al., 2016a).

144 Persons with aphasia have also been shown to use more iconic gestures during a cartoon narration

145 task compared with a spontaneous conversation (de Beer et al., 2019), supporting the Gesture as

146 Simulated Action framework, which predicts that speakers gesture more when speech is based on

147 imagery (Hostetter \& Alibali, 2019).

148 Evaluating task effects is clinically and theoretically meaningful. It is well acknowledged that

149 spoken language is task-specific, i.e., that the microlinguistic and functional (macrostructural)

150 aspects of spoken language shift according to task demands (Dalton \& Richardson, 2019; Li et al.,

151 1996; Shadden et al., 1990; Stark, 2019a; Ulatowska et al., 1981). For that reason, it is best practice

152 to employ a variety of tasks to most comprehensively evaluate spoken language ability (Brookshire

$153 \&$ Nicholas, 1994; Stark, 2019a). It follows that employing a variety of tasks to assess a person's

154 co-speech gesturing is important.

155 Further, evaluating the extent to which task influences gesture can lend valuable information

156 toward planning treatment, e.g., provide information to the clinician regarding typical gesture use,

157 as well as atypical or inaccurate gesture use at a task-specific level. Presently, gesture-based or

158 gesture-integrative therapies are few, and these therapies have largely not resulted in significant

159 improvement in spoken language in aphasia (Rose et al., 2013). One such reason may be our lack 
160 of understanding about task-specific gesturing. Therefore, directly comparing gesture use between

161 tasks in the same person will allow us to understand gesture use more sensitively and

162 comprehensively, as well as the relationship between task and gesture. Doing so in naturalistic

163 tasks can also lend critical insight about how gesture is used in a spontaneously communicative

164 sense, rather than in a more heavily constrained or structured task. Finally, if we can understand

165 the extent to which gestures are produced across a range of naturalistic tasks in aphasia, and how

166 these gestures relate to spoken language competency, we can more accurately formulate predictive

167 hypotheses regarding language recovery. For example, we can answer clinically critical questions

168 like: to what extent does iconic gesturing during narrative in the acute phase of aphasia predict

169 communicative success in the chronic stage of aphasia (or indeed, predict in which individual's

$170 \quad$ aphasia will resolve)?

171 Evaluating task-specific gesturing also has critical importance for theories related to gesture

172 use in typical populations, as well as those with language impairments. Some discourse tasks

173 employ pictures, which in turn may facilitate different patterns of gesturing — for example, a trend

174 toward more concrete/deictic gestures, rather than iconic gestures. In tandem, picture-oriented

175 tasks may elicit more nouns and simpler language structure than other tasks (Stark, 2019a). For

176 speakers with more severe aphasia, certain tasks can elicit more spoken output than less structured

177 tasks (Stark \& Fukuyama, 2020). It is therefore of interest to compare gesture usage across tasks

178 with varying cognitive and linguistic complexity, and to evaluate the interaction between gesture

179 production, task, and the linguistic and cognitive characteristics of speakers. For example, iconic

180 gesturing may be used more often, and with a greater success rate, when tasks do not involve other

181 visual stimuli (e.g., picture descriptions), as iconic gestures may 'stand in' for the absent visual,

182 concrete imagery. But, this may only hold true for individuals who have impoverished post- 
183 conceptual linguistic processes, but not necessarily those who have impoverished pre-conceptual 184 knowledge.

\section{Research Questions}

186 In this study, we address some of these research gaps, comparing iconic gestures made by 187 persons with aphasia during two monologic discourse tasks: a procedural narrative and an 188 expository, picture sequence description. We investigate two research questions:

189 1. To what extent does frequency and rate of iconic gesture differ between two spoken 190 discourse tasks, i.e., is there a main effect of task on gesture?

1912 2. To what extent does frequency and rate relate to spoken language, and is this relationship $192 \quad$ specific to task?

193 


\section{Participants}

196 Participant data were collected from AphasiaBank, a password protected database for researchers

197 interested in spoken discourse use in aphasia (MacWhinney et al., 2011). Inclusion criteria

198 included members of the Aphasia subset within AphasiaBank, all of whom had acquired brain

199 damage and aphasia (or latent aphasia) as per clinical assessment and standardized testing scores.

200 Included participants spoke English as their primary language and had audiovisual data for both

201 tasks $(\mathrm{N}=303$ persons had data for the picture sequence task, and $\mathrm{N}=234$ persons for the procedural

202 task; $\mathrm{N}=233$ people had data for both tasks). In AphasiaBank, some participants have data for

203 multiple timepoints (tagged as ' $a$ ' [first timepoint], ' $b$ ' [second timepoint], and so on). For this

204 study, we included data from only the first timepoint for each participant.

205 We then excluded participants for whom their video (for either task) did not show the 206 entirety of both upper limbs, or where the angle of the video did not allow for complete gesture

207 viewing. This was necessary to ensure accurate gesture coding. We then excluded persons with 208 aphasia who did not produce an iconic gesture during at least one task of interest. With these 209 exclusion criteria, $\sim \mathrm{N}=98$ were excluded. Finally, participants were excluded if they were given a 210 picture aid for the "Sandwich" procedural discourse (described in more detail in section Stimuli).

211 This decision was made because not every individual was given this additional visual support 212 (roughly $\sim 20 \%$ of the database received a picture during the Sandwich task, $\sim \mathrm{N}=60$ ). As we wanted

213 to evaluate the difference in gesture usage between discourse genres, and only the picture sequence 214 task was meant to include a visual aid, inclusion of those individuals with a visual aid during the 215 procedural "Sandwich" task was inconsistent. 
217 aphasia, who are further described in Table 1.

\section{TABLE 1 HERE}

\section{Stimuli}

220 To evaluate our first research question (evaluate a main effect of task on iconic gesture frequency

221 and rate), gestures were analyzed during two spontaneous speech discourse tasks, drawn from the 222 AphasiaBank protocol (MacWhinney et al., 2011), called the "Sandwich" and the "Window" tasks.

223 These two tasks were chosen (1) based on prior research out of our lab implicating cognitive and

224 linguistically different requirements per task (Stark, 2019b; Stark \& Fukuyama, 2020), and (2)

225 because these tasks are less frequently explored in aphasia gesture research.

226 The "Sandwich" task was a procedural narrative, in which participants described how to 227 make a peanut butter and jelly sandwich. As noted earlier, this task did not include any visual aids.

228 The instructions for the Sandwich task were as follows: "Let's move on to something a little 229 different. Tell me how you would make a peanut butter and jelly sandwich.” If no response in 10 230 seconds was given, the examiner gave a second prompt: "If you were feeling hungry for a peanut 231 butter and jelly sandwich, how would you make it?" If no response was given, the examiner 232 utilized a set of Troubleshooting questions (available on aphasia.talkbank.org).

233 The "Broken Window" task (shortened, here, to 'Window') was a descriptive task 234 (specifically, a picture sequence description), in which participants described a sequence of four 235 pictures: a boy kicking a soccer ball through a picture window, knocking over a lamp and 236 surprising a sitting man (Menn et al., 1998). The instructions for the Window task were as follows:

237 "Now I'm going to show you these pictures." The examiner then presents picture series. "Take a 238 little time to look at these pictures. They tell a story. Take a look at all of them, and then I'll ask 
239 you to tell me the story with a beginning, a middle, and an end. You can look at the pictures as you

240 tell the story." If no response was given in 10 seconds, the examiner gave a second prompt: "Take

241 a look at this picture (point to first picture) and tell me what you think is happening." If needed,

242 the examiner pointed to each picture sequentially, giving the prompt: "And what happens here?"

243 For each panel, if no response, the examiner provided the prompt: "Can you tell me anything about

244 this picture?" If no response was given to any of these prompts, the examiner utilized a set of

245 Troubleshooting questions (available on aphasia.talkbank.org).

\section{Gesture Coding}

\section{Gesture Types}

248 Iconic gestures represent meaning that is closely related to the semantic content of the speech that

249 they accompany - indeed, these forms of gesture can only be interpreted within the context of 250 speech, unlike other gestures which are imitations of motor actions (i.e., pantomimes) or carry 251 culturally-specific meaning on their own (i.e., emblems) (McNeill, 1992). We drew our definition

252 and coding parameters from Sekine and Rose (2013), classifying viewpoint, referential, and 253 metaphoric gesture types as iconic. Viewpoint gestures are those that depict a concrete action, 254 event, or object as though the speaker is observing it from afar (observer viewpoint) or as though 255 he is the character/object itself (character viewpoint) (McNeill, 1992). Referential gestures are 256 those that place objects, places, or characters in the story, into the space in front of a speaker where 257 any concrete object is absent, typically taking the form of a pointing gesture or of the hand 258 'holding' some entity (Gullberg, 2006). Metaphoric gestures convey meaning in a non-literal, 259 abstract way, and are typically regarded as a form of iconic gesture with abstract content (Kita, 260 2014). Note that, during our gesture coding, we did not differentiate between referential and 
261 metaphoric gestures. These were scored as a single type (referential + metaphoric type). Examples

262 of iconic gestures demonstrated in this study are shown in Table S1.

263 Note that we also coded three other gesture types, which are not reported in detail here, but

264 can be found in Table S2. These were concrete deictic (i.e., a concrete referent in the physical

265 environment, such as a picture; McNeil, 1992), emblem (i.e., a culturally-specific gesture where

266 form and meaning can usually be understood without speech; Kendon, 1980), and number (i.e.,

267 using the speakers fingers to represent numbers; Cicone et al., 1979).

\section{Gesture Coding}

269 Gestures were coded using the online Browsable Database on AphasiaBank. The Browsable

270 Database time locks each spoken utterance with the video of the participant, allowing the 271 experimenter to watch the video whilst also reading verbatim transcribed speech. Author $\mathrm{CC}$ was

272 the primary coder. She watched all videos through once prior to coding. Then, she watched each

273 video in 10 second chunks, tallying frequencies by gesture type (viewpoint, referential + 274 metaphoric, concrete deictic, number, and emblem). Each video was coded in this way twice, to 275 check for coding consistency. A unit of gesture was defined as the duration from the start of a 276 movement until the hand(s) returned to its resting position (McNeill, 1992). If the hand(s) did not

277 return to the resting position, gestures were divided by either a pause in the movement or an 278 obvious change in shape or trajectory (Jacobs \& Garnham, 2007). Note that many gesture types 279 were not recorded for the purposes of this study, including beats and other non-gesture movements 280 (e.g., self-adjusting, touching hair, touching table).

\section{Raters and Reliability}

282 The primary rater (author $\mathrm{CC}$ ) trained two additional undergraduate raters in gesture coding. These 283 raters practiced coding on a random sample of ten subjects (they trained on a combination of 
284 samples from an aphasia group and a neurotypical group from AphasiaBank). Author CC then

285 cross-checked coding to establish inter-rater reliability of at least $80 \%$ agreement on these practice

286 samples. Any disagreements were discussed between all raters and a consensus was arrived at.

287 Following resolution of any outstanding issues, raters were then assigned approximately 25 total

288 individuals ( $22 \%$ of total sample, not including any samples used to practice) to rate. Though

289 reliability was established on a training set, we further established inter-rater reliability on $10 \%$ of

290 this sample ( $\mathrm{N}=3$ subjects). Inter-rater reliability exceeded a Pearson's correlation of $r>75$

291 between primary rater CC and each auxiliary rater, for frequency of each gesture type. In sum, all

292 raters trained on a training set prior to rating achieving $>80 \%$ agreement across the entire training

293 set), and then inter-rater agreement was calculated for $10 \%$ of the study sample, demonstrating

294 that training set reliability extended to the study sample. Given complexities and idiosyncrasies of

295 gesture rating (e.g., some level of subjectivity, as described by McNeil 1992), we consider this

296 favorable evidence of rater reliability, whilst also acknowledging the small 'n' on which reliability

297 was computed.

298 Spoken Language Data and Fluency

299 To evaluate our second research question (evaluate the relationship between iconic gesture

300 frequency and rate with spoken language), we acquired information about spoken language

301 produced during the discourse tasks, and extracted extra-task information about language fluency

302 from a standardized testing battery.

303 Our primary interest was to measure the relationship between iconic gesture and language

304 dysfluency, by task. When gesture is prohibited in neurotypical speakers, more dysfluencies (e.g.,

305 pauses, slower speech rate, false starts, fillers) are produced. In persons living with aphasia,

306 increased frequency of gesture is thought to improve lexical retrieval. That is, gestures are 
307 produced in higher rates when language is particularly dysfluent. Here, we postulate that 308 production of iconic gestures will accompany greater dysfluencies, in accordance with this 309 hypothesis. For the purposes of this study, we explore common dysfluencies found in aphasic 310 speech, and which have been previously evaluated in studies of gesture use in persons with aphasia 311 and neurotypical participants (Carlomagno \& Cristilli, 2006; de Beer et al., 2019; Feyereisen,

312 1983; Kong et al., 2017; Kong et al., 2015; Rauscher et al., 1996): hesitations, comprised of filled 313 and unfilled pauses of greater than three seconds, false starts, and fillers; and words per minute, a

314 metric of speaking rate. Hesitations were computed as a proportion of total words produced, 315 inclusive of retracings and repetitions. We likewise evaluated metrics of gross language output, 316 including speaking time and total utterances, to evaluate the relationship of iconic gesture with 317 speech. To obtain this spoken language data, we extracted variables from each task's language 318 sample using CLAN (MacWhinney, 2018).

319 Complementary to the linguistic information extracted from the discourse tasks, we also 320 used a metric of language fluency obtained from a neuropsychological test battery as a means of 321 evaluating extra-task spoken language fluency (i.e., a metric of language fluency derived from a 322 different task, and scored based on a standardized scale). Specifically, we extracted extra-task 323 information about language fluency from the Fluency, Grammatical Competence, and Paraphasias 324 of Spontaneous Speech score (we will call this the "Fluency" score for short) of the Western 325 Aphasia Battery - Revised (WAB-R). The Fluency score is obtained by first having subjects 326 answer conversational questions (e.g., "Have you been here before?" and "What is your 327 occupation?"), followed by having subjects describe a picture. The test administrator then ranks 328 subjects' fluency from 0 to 10 , described below. Using these Fluency scores, we created three 329 fluency groups: a group containing subjects with low fluency ("low fluency" group, scores 0-4), a 
group containing subjects that are fluent but whose speech is characterized by errors, jargon, and

331 empty speech ("fluency with errors" group, scores 5-7), and a group whose subjects are highly

332 fluent with few errors ("high functional fluency" group, scores 8-10). The fluency descriptions

333 from the WAB-R are briefly described (Kertesz, 2007):

334 - Low fluency group (scores $0-4$ ): A score of 0 reflects no words or short, meaningless

335 utterances; a score of 1 reflects recurrent, brief, stereotypic utterances with varied intonation,

336 where emphasis or prosody may carry some meaning; a score of 2 reflects single words, usually

337 errors (paraphasias), with speech being effortful and hesitant; a score of 3 reflects longer,

338 recurrent stereotypic or automatic utterances lacking in information; and a score of 4 reflects

339 halting, telegraphic speech containing mostly single words, paraphasias, some prepositional

340 phrases, with severe word-finding difficulty. A stipulation for a score of 4 is that no more than

341 two complete sentences may be present (excepting automatic sentences).

342 - Fluent with errors group (scores 5-7): A score of 5 reflects telegraphic but more fluent speech,

343 containing some grammatical organization, though still with marked word-finding difficulty

344 and paraphasias; a score of 6 reflects more propositional sentences with normal syntactic

345 patterns, coupled with paraphasias (optional) and significant word-finding difficulty and/or

346 hesitations; and a score of 7 reflects fluent, phonemic jargon with semblance to English syntax

347 and rhythm, alongside varied phonemes and neologisms.

348 - High functional fluency group (scores 8 - 10): A score of 8 reflects circumlocutory, fluent 349 speech, with moderate word-finding difficulty, with or without paraphasias, and may present 350 with semantic jargon; a score of 9 reflects mostly complete, relevant sentences, with occasional 351 hesitations and/or paraphasias and some word-finding difficulty; and a score of 10 reflects 352 sentences of normal length and complexity, without definite slowing, halting or paraphasias. 


\section{Analyses and Research Questions}

354 All analyses were conducted in SPSS 27. The data were, overall, not normal in distribution, and 355 we therefore employed non-parametric statistics (specifically: Spearman correlation, Chi-square

356 tests, Wilcoxon Signed Rank tests for repeated measures, and Kruskal-Wallis H tests of

357 independent samples). Specific tests are described in more detail in each appropriate section. All

358 analyses were corrected for multiple comparisons using Bonferroni correction; specific correction

$359 \mathrm{p}$-values are noted in the text. The current study was not pre-registered, which we acknowledge as

360 a limitation.

361 Recall that we had two primary research questions. The first research question is theoretically

362 driven: Do iconic gesture frequency and rate significantly differ between two narrative tasks, i.e.,

363 is there a main effect of task on gesture, similar to the effect of task demonstrated on the speech

364 of persons living with aphasia (Stark, 2019a; Stark \& Fukuyama, 2020)? The second research

365 question is also theoretically driven, given prior work examining the relationship of iconic gesture

366 with spoken language in aphasia (Dipper et al., 2011; Pritchard et al., 2015; Sekine \& Rose, $2013 a$ ).

367 Therefore, our second research question is: To what extent are task-specific iconic gesture

368 frequency and rate related to spoken language? As such, the primary dependent variables of this

369 study were iconic gesture frequency (i.e., how many gestures were produced) and rate (i.e., how

370 many gestures were produced per spoken word, including repetitions/retracings of words and 371 paraphasias with no known targets) (see Table 1).

372 In addition to evaluating our primary research questions, we explore the relationship of

373 iconic gesture frequency with demographic variables (e.g., age). We additionally provide

374 exploratory analyses that divide iconic gestures into two types ([1] viewpoint and [2] referential +

375 metaphoric), which is motivated by differences in theoretical constructs between gesture types. 
376 Given that the study of gesture in aphasia is a blossoming field, it remains unclear the extent to

377 which factors like gesture type and/or discourse task may be meaningful in delineating the

378 relationship of spoken language and gesture usage in this population. We did not explicitly

379 differentiate between referential and metaphoric gestures for the purposes of this study, and thus

380 they will be presented as a combined group. The goal of this exploratory analysis is to provide

381 preliminary evidence for future investigations about the relationship of iconic gesture type 382 frequency with task, and with language variables, in PWA.

\section{Results}

384 Below, we present analyses for the whole $(\mathrm{N}=75)$ sample. Additionally, we present results for a 385 smaller sample $(\mathrm{N}=43)$, who gestured during both Window and Sandwich tasks; we call this 386 sample the "matched" group. We present both sets of results to provide future researchers with a 387 wealth of data. Throughout the results, we will draw attention to instances where the findings from 388 these two groups diverge.

389 Relationship Between Iconic Gesture and Demographic Information

We evaluated the relationship between iconic gesture frequency and demographic and 391 neuropsychological information. After multiple comparison correction using Bonferroni 392 correction ( $\mathrm{p}<.01,5$ comparisons), none of the following significantly associated with total iconic 393 gesture frequency, summed across the two tasks: aphasia severity (measured by Western Aphasia 394 Battery Revised Aphasia Quotient) (Kertesz, 2007) ( $\left.\mathrm{N}=75, \mathrm{r}_{\mathrm{s}}=.10, \mathrm{p}=.38\right)$, years of speech395 language therapy $\left(\mathrm{N}=75, \mathrm{r}_{\mathrm{s}}=.21, \mathrm{p}=.07\right)$, education $\left(\mathrm{N}=75, \mathrm{r}_{\mathrm{s}}=.21, \mathrm{p}=.08\right)$, or age $\left(\mathrm{N}=75, \mathrm{r}_{\mathrm{s}}=-.26\right.$, $396 \mathrm{p}=.02$ ). Aphasia duration - that is, the amount of time one has lived with aphasia - did significantly 397 correlate with total iconic gesture frequency $\left(\mathrm{N}=75, \mathrm{r}_{\mathrm{s}}=.36, \mathrm{p}=.002\right)$, indicating that persons with 398 more chronic aphasia tended to produce iconic gestures more frequently. Further exploration by 
discourse task suggested that the relationship between aphasia duration and gesture frequency was

400 most related to iconic gesturing on the Window task $\left(\mathrm{N}=75, \mathrm{r}_{\mathrm{s}}=.37, \mathrm{p}=.001\right)$ and not the Sandwich

401 task $\left(\mathrm{N}=75, \mathrm{r}_{\mathrm{s}}=.21, \mathrm{p}=.07\right)$. Hemiparesis could be one reason why gestures are not produced

402 frequently, or at a high rate (although, this typically is not the case, e.g., Kong et al., 2015). We

403 evaluated the impact of physical status (no motor impairment; unilateral hemiparesis; unilateral

404 hemiplegia) on iconic gesture frequency pooled across tasks, finding no significant difference in

405 iconic gesture frequency across different motor impairments (Independent-Samples Kruskal-

406 Wallis Test, $\mathrm{N}=74$ [1 missing datapoint], $\mathrm{W}=2.16, \mathrm{p}=.34$ ). We also performed an explorative

407 analysis on the impact of gender on iconic gesture frequency, as there is evidence from psychology

408 that women tend to employ more nonverbal communication (Hall \& Gunnery, 2013), finding no

409 significant difference in iconic gesture frequency between males and females (Mann-Whitney U-

410 Test, $\mathrm{N}=75, \mathrm{U}=.63, \mathrm{p}=.53)$.

411 We likewise evaluated the relationship of gesture rate with demographic and

412 neuropsychological information. After multiple comparison correction using Bonferroni

413 correction ( $\mathrm{p}<.01,5$ comparisons), average iconic gesture rate (i.e., rate averaged across tasks) was

414 found to not significantly associate with aphasia severity $\left(\mathrm{N}=75, \mathrm{r}_{\mathrm{s}}=-.19, \mathrm{p}=.10\right)$, age $\left(\mathrm{N}=75, \mathrm{r}_{\mathrm{s}}=-\right.$

$415.28, \mathrm{p}=.01)$, or education $\left(\mathrm{N}=75, \mathrm{r}_{\mathrm{s}}=-.11, \mathrm{p}=.36\right)$, but significantly with years of speech-language

416 therapy $\left(\mathrm{N}=75, \mathrm{r}_{\mathrm{s}}=.37, \mathrm{p}=.001\right)$ and aphasia duration $\left(\mathrm{N}=75, \mathrm{r}_{\mathrm{s}}=.40, \mathrm{p}<.001\right)$. Further exploration

417 by task indicated that aphasia duration was positively related to gesture rate for each task (Window,

$418 \mathrm{~N}=75, \mathrm{r}_{\mathrm{s}}=.40, \mathrm{p}<.001$; Sandwich, $\mathrm{N}=75, \mathrm{r}_{\mathrm{s}}=.25, \mathrm{p}=.03$ ), whilst the relationship between years of

419 speech-language therapy and gesture rate was driven by performance on the Sandwich task

420 (Window, $N=75, r_{s}=.22, p=.06$; Sandwich, $N=75, r_{s}=.31, p=.007$ ). We did find a significant

421 relationship between motor impairment and gesture rate (Independent-Samples Kruskal-Wallis 
422 Test, $\mathrm{N}=74[\mathrm{~N}=1$ missing data], $\mathrm{W}=13.85, \mathrm{p}=.001$ ). Pairwise comparisons (corrected at Bonferroni

$423 \mathrm{p}<.01$ for 3 comparisons) in $\mathrm{N}=74$ showed that persons with hemiplegia tended to gesture at a

424 higher rate than persons with no motor impairment $(\mathrm{p}<.001)$, which seems counterintuitive but

425 makes sense in the context that those with hemiplegia also tend to be those who produce fewer 426 words ( $\mathrm{W}=7.47, \mathrm{p}=.02$; where persons with hemiplegia produced significantly fewer words than

427 those with no motor impairment, $\mathrm{p}=.006$ ). We did not find a significant difference in gesture rate 428 between males and females (Mann-Whitney U-Test, $\mathrm{N}=75, \mathrm{U}=-1.87, \mathrm{p}=.06$ ).

429 Note that our matched group $(\mathrm{N}=43)$ had a similar correlation matrix. Correlation tables 430 between demographic variables, language variables, and gesture variables, are shown in Table S3 431 ( $\mathrm{N}=75$ group) and Table $\mathrm{S} 4(\mathrm{~N}=43$ group).

\section{Main Effect of Task on Iconic Gesture}

433 Here, we evaluate our primary research question, which is the main effect of task on iconic 434 gesture frequency and rate. Of our entire sample $(\mathrm{N}=75), 57.3 \%$ of subjects made an iconic gesture 435 during the Window task, whilst 100\% made an iconic gesture during the Sandwich task (Table 2).

Employing Wilcoxon Signed Rank tests, which is a nonparametric repeated measures 438 analysis, we identified a significant difference between tasks in gesture frequency $(N=75, Z=3.45$, $439 \mathrm{p}=.001 ; \mathrm{N}=43, \mathrm{Z}=4.98, \mathrm{p}<.001)$ and gesturing rate $(\mathrm{N}=75, \mathrm{Z}=7.36, \mathrm{p}<.001 ; \mathrm{N}=43, \mathrm{Z}=5.42, \mathrm{p}<.001)$

440 (Bonferroni, $\mathrm{p}<.025,2$ comparisons per group) (Table 3). For a distribution of gesture frequency 441 and rate in all subjects $(\mathrm{N}=75)$, see Figure 1. These results demonstrate a clear main effect of task, 442 specifically greater iconic gesture frequency and rate during the Sandwich task. 
An exploratory analysis to identify the extent to which iconic gesture type frequency

445 differed between tasks demonstrated that referential + metaphoric gestures were produced 446 significantly more often during the Sandwich task $(N=75, Z=-6.48, p<.001 ; N=43, Z=-4.73$, $447 \mathrm{p}<.001$ ), and this was also true for viewpoint gestures, which were made more often during the 448 Sandwich task $(\mathrm{N}=75, \mathrm{Z}=-6.33, \mathrm{p}<.001 ; \mathrm{N}=43, \mathrm{Z}=-3.97, \mathrm{p}<.001)$ (Bonferroni, $\mathrm{p}<.025,2$ 449 comparisons per group). This finding shows that not a single iconic gesture type drove the 450 difference in gesture frequency between the tasks.

451 Further exploratory analyses of iconic gesture rate in the whole group demonstrated that 452 referential + metaphoric gestures were produced at a significantly higher rate during the Sandwich $453 \operatorname{task}(\mathrm{N}=75, \mathrm{Z}=6.43, \mathrm{p}<.001 ; \mathrm{N}=43, \mathrm{Z}=-4.63, \mathrm{p}<.001)$ and this was likewise the case for viewpoint 454 gestures $(\mathrm{N}=75, \mathrm{Z}=-6.91, \mathrm{p}<.001 ; \mathrm{N}=43, \mathrm{Z}=-4.76, \mathrm{p}<.001)$ (Bonferroni, $\mathrm{p}<.025,2$ comparisons 455 per group). This finding again suggests that not a single iconic gesture type drove the difference 456 in gesture rate between the tasks.

TABLE 3 HERE

\section{Relationship Between Iconic Gesture and Spoken Language}

459 Relationship of Iconic Gesture with Fluency Variables Extracted from Discourse

460 Our second research prerogative was to identify relationships between spoken language 461 and iconic gesture frequency and rate. Given a main effect of task, we evaluated the relationship 462 between iconic gesture and language variables, stratified by task.

463 In regards to task-related differences in spoken language, Wilcoxon Signed Rank tests 464 evaluating repeated measures demonstrated that the Window task had a significantly longer 465 speaking time than the Sandwich task $(N=75, Z=-2.65, p=.008 ; N=43, Z=-2.88, p=.004)$, but there 466 were no significant differences between the two tasks for any other language metric: total 
467 utterances $(\mathrm{N}=75, \mathrm{Z}=-2.01, \mathrm{p}=.045 ; \mathrm{N}=43, \mathrm{Z}=-2.10, \mathrm{p}=.036)$, words per minute $(\mathrm{N}=75, \mathrm{Z}=-.75$, $468 \mathrm{p}=.46 ; \mathrm{N}=43, \mathrm{Z}=-.27, \mathrm{p}=.79)$, or proportion hesitations $(\mathrm{N}=75, \mathrm{Z}=.69, \mathrm{p}=.49 ; \mathrm{N}=43, \mathrm{Z}=1.49$, $469 \mathrm{p}=.14$ ) (Bonferroni correction, $\mathrm{p}<.0125,4$ comparisons per subject group). We show descriptive 470 statistics and statistical information for the $\mathrm{N}=75$ whole group and the $\mathrm{N}=43$ matched group in $471 \quad$ Table 4.

TABLE 4 HERE

\section{Gesture Frequency's Relationship with Language Fluency Variables.}

For the Sandwich task, we identified a significant relationship between gesture frequency $\left.476 \mathrm{p}<.001 ; \mathrm{N}=43, \mathrm{r}_{\mathrm{s}}=.63, \mathrm{p}<.001\right)$, but not words per minute $\left(\mathrm{N}=75, \mathrm{r}_{\mathrm{s}}=.10, \mathrm{p}=.39 ; \mathrm{N}=43, \mathrm{r}_{\mathrm{s}}=.07\right.$, $477 \mathrm{p}=.67)$ or proportion hesitations $\left(\mathrm{N}=75, \mathrm{r}_{\mathrm{s}}=.08, \mathrm{p}=.49 ; \mathrm{N}=43, \mathrm{r}_{\mathrm{s}}=.06, \mathrm{p}=.72\right)$ (Bonferroni 478 correction, $\mathrm{p}<.0125,4$ comparisons per subject group). As an exploratory analysis, we evaluated 479 the correlation between language metrics and frequency of gesture types (viewpoint; referential + 480 metaphoric), finding that viewpoint gesture frequency during the Sandwich task significantly 481 correlated with speaking time $\left(\mathrm{N}=75, \mathrm{r}_{\mathrm{s}}=.63, \mathrm{p}<.001 ; \mathrm{N}=43, \mathrm{r}_{\mathrm{s}}=.56, \mathrm{p}<.001\right)$ and total utterances $482\left(\mathrm{~N}=75, \mathrm{r}_{\mathrm{s}}=.59, \mathrm{p}<.001 ; \mathrm{N}=43, \mathrm{r}_{\mathrm{s}}=.59, \mathrm{p}<.001\right)$, but not with our fluency variables: words per minute $483\left(\mathrm{~N}=75, \mathrm{r}_{\mathrm{s}}=-.17, \mathrm{p}=.16 ; \mathrm{N}=43, \mathrm{r}_{\mathrm{s}}=-.19, \mathrm{p}=.21\right)$ or proportion hesitations $\left(\mathrm{N}=75, \mathrm{r}_{\mathrm{s}}=.18, \mathrm{p}=.13 ; \mathrm{N}=43\right.$, $484 \mathrm{r}_{\mathrm{s}}=.32, \mathrm{p}=.04$ ) (Bonferroni correction, $\mathrm{p}<.0125,4$ comparisons per subject group). Referential + 485 metaphoric gesture frequency during Sandwich also significantly correlated with speaking time $486\left(\mathrm{~N}=75, \mathrm{r}_{\mathrm{s}}=.30, \mathrm{p}=.008 ; \mathrm{N}=43, \mathrm{r}_{\mathrm{s}}=.42, \mathrm{p}=.005\right)$ and total utterances [only for large group] $(\mathrm{N}=75$, $\left.487 \mathrm{r}_{\mathrm{s}}=.42, \mathrm{p}<.001 ; \mathrm{N}=43, \mathrm{r}_{\mathrm{s}}=.35, \mathrm{p}=.02\right)$ and, in contrast to viewpoint gesture frequency, approached 488 a significant correlation with proportion hesitations ( $\left.\mathrm{N}=75, \mathrm{r}_{\mathrm{s}}=-.29, \mathrm{p}=.013 ; \mathrm{N}=43, \mathrm{r}_{\mathrm{s}}=-.24, \mathrm{p}=.13\right)$ 
and words per minute $\left(\mathrm{N}=75, \mathrm{r}_{\mathrm{s}}=.27, \mathrm{p}=.019 ; \mathrm{N}=43, \mathrm{r}_{\mathrm{s}}=.28, \mathrm{p}=.07\right)$ (Bonferroni correction, $490 \mathrm{p}<.0125,4$ comparisons per subject group).

For the Window task, we found a significant relationship between gesture frequency and 492 speaking time [only for large group] $\left(\mathrm{N}=75, \mathrm{r}_{\mathrm{s}}=.34, \mathrm{p}=.003 ; \mathrm{N}=43, \mathrm{r}_{\mathrm{s}}=.29, \mathrm{p}=.06\right)$ and total 493 utterances [only for large group] $\left(\mathrm{N}=75, \mathrm{r}_{\mathrm{s}}=.45, \mathrm{p}<.001 ; \mathrm{N}=43, \mathrm{r}_{\mathrm{s}}=.32, \mathrm{p}=.03\right)$, but not words per 494 minute $\left(\mathrm{N}=75, \mathrm{r}_{\mathrm{s}}=-.09, \mathrm{p}=.44 ; \mathrm{N}=43, \mathrm{r}_{\mathrm{s}}=-.24, \mathrm{p}=.13\right)$, or proportion hesitations $\left(\mathrm{N}=75, \mathrm{r}_{\mathrm{s}}=-.13\right.$, $495 \mathrm{p}=.25 ; \mathrm{N}=43, \mathrm{r}_{\mathrm{s}}=.006, \mathrm{p}=.97$ ) (Bonferroni correction, $\mathrm{p}<.0125,4$ comparisons per subject group). 496 As an exploratory analysis, we evaluated the correlation between language metrics and frequency 497 of gesture types (viewpoint; referential + metaphoric), finding that viewpoint gesture frequency 498 during the Window task significantly correlated with total utterances [only for large group] (N=75, $\left.499 \mathrm{r}_{\mathrm{s}}=.36, \mathrm{p}=.001 ; \mathrm{N}=43, \mathrm{r}_{\mathrm{s}}=.21, \mathrm{p}=.18\right)$ but not speaking time $\left(\mathrm{N}=75, \mathrm{r}_{\mathrm{s}}=.23, \mathrm{p}=.04 ; \mathrm{N}=43, \mathrm{r}_{\mathrm{s}}=.15\right.$, $500 \mathrm{p}=.33)$, words per minute $\left(\mathrm{N}=75, \mathrm{r}_{\mathrm{s}}=-.10, \mathrm{p}=.39 ; \mathrm{N}=43, \mathrm{r}_{\mathrm{s}}=-.21, \mathrm{p}=.19\right)$ or proportion hesitations $501\left(\mathrm{~N}=75, \mathrm{r}_{\mathrm{s}}=-.01, \mathrm{p}=.92 ; \mathrm{N}=43, \mathrm{r}_{\mathrm{s}}=.19, \mathrm{p}=.24\right)$ (Bonferroni correction, $\mathrm{p}<.0125,4$ comparisons per 502 subject group). Referential + metaphoric gesture frequency significantly correlated with total 503 utterances $\left(\mathrm{N}=75, \mathrm{r}_{\mathrm{s}}=.45, \mathrm{p}<.001 ; \mathrm{N}=43, \mathrm{r}_{\mathrm{s}}=.40, \mathrm{p}=.007\right)$ as well as speaking time $\left(\mathrm{N}=75, \mathrm{r}_{\mathrm{s}}=.39\right.$, $\left.504 \mathrm{p}=.001 ; \mathrm{N}=43, \mathrm{r}_{\mathrm{s}}=.40, \mathrm{p}=.008\right)$, but not words per minute $\left(\mathrm{N}=75, \mathrm{r}_{\mathrm{s}}=-.07, \mathrm{p}=.57 ; \mathrm{N}=43, \mathrm{r}_{\mathrm{s}}=-.14\right.$, $505 \mathrm{p}=.36)$ or proportion hesitates $\left(\mathrm{N}=75, \mathrm{r}_{\mathrm{s}}=-.29, \mathrm{p}=.01 ; \mathrm{N}=43, \mathrm{r}_{\mathrm{s}}=-.30, \mathrm{p}=.06\right)$ (Bonferroni correction, $506 \mathrm{p}<.0125,4$ comparisons per subject group). the case for both tasks. 


\section{Gesture Rate's Relationship with Language Fluency Variables.}

We then evaluated the relationship between gesture rate and language variables, finding

512 that gesture rate during the Sandwich task demonstrated a significant relationship with our fluency

513 variables, words per minute [only for large group] $\left(\mathrm{N}=75, \mathrm{r}_{\mathrm{s}}=-.47, \mathrm{p}<.001 ; \mathrm{N}=43, \mathrm{r}_{\mathrm{s}}=-.36, \mathrm{p}=.017\right)$

514 and proportion hesitations [only for large group] $\left(\mathrm{N}=75, \mathrm{r}_{\mathrm{s}}=.34, .003 ; \mathrm{N}=43, \mathrm{r}_{\mathrm{s}}=.37, \mathrm{p}=.02\right)$, but

515 did not significantly correlate with our gross output variables, speaking time $\left(\mathrm{N}=75, \mathrm{r}_{\mathrm{s}}=-.06, \mathrm{p}=.64\right.$;

$\left.516 \mathrm{~N}=43, \mathrm{r}_{\mathrm{s}}=-.16, \mathrm{p}=.32\right)$ or total utterances $\left(\mathrm{N}=75, \mathrm{r}_{\mathrm{s}}=-.21, \mathrm{p}=.07 ; \mathrm{N}=43, \mathrm{r}_{\mathrm{s}}=-.26, \mathrm{p}=.09\right)$ (Bonferroni

517 correction, $\mathrm{p}<.0125,4$ comparisons per subject group). Exploratory analyses demonstrated that

518 viewpoint gesture rate did not significantly associate with speaking duration $\left(\mathrm{N}=75, \mathrm{r}_{\mathrm{s}}=.04, \mathrm{p}=.71\right.$;

$\left.519 \mathrm{~N}=43, \mathrm{r}_{\mathrm{s}}=-.06, \mathrm{p}=.70\right)$ or total utterances $\left(\mathrm{N}=75, \mathrm{r}_{\mathrm{s}}=-.13, \mathrm{p}=.25 ; \mathrm{N}=43, \mathrm{r}_{\mathrm{s}}=-.10, \mathrm{p}=.53\right)$; approached

520 a significant relationship with words per minute in the matched group and was significantly related

521 to words per minute in the whole group $\left(\mathrm{N}=75, \mathrm{r}_{\mathrm{s}}=-.49, \mathrm{p}<.001 ; \mathrm{N}=43, \mathrm{r}_{\mathrm{s}}=-.37, \mathrm{p}=.015\right)$; and was

522 significantly, positively related to proportion hesitations $\left(\mathrm{N}=75, \mathrm{r}_{\mathrm{s}}=.43, \mathrm{p}<.001 ; \mathrm{N}=43, \mathrm{r}_{\mathrm{s}}=.44\right.$, $523 \mathrm{p}=.003$ ) (Bonferroni correction, $\mathrm{p}<.0125,4$ comparisons per subject group). Referential + 524 metaphoric gesture rate was not significantly associated with speaking duration $\left(\mathrm{N}=75, \mathrm{r}_{\mathrm{s}}=-.007\right.$, $\left.525 \mathrm{p}=.95 ; \mathrm{N}=43, \mathrm{r}_{\mathrm{s}}=-.001, \mathrm{p}>.99\right)$, total utterances $\left(\mathrm{N}=75, \mathrm{r}_{\mathrm{s}}=-.05, \mathrm{p}=.68 ; \mathrm{N}=43, \mathrm{r}_{\mathrm{s}}=-.16, \mathrm{p}=.32\right)$, words 526 per minute $\left(\mathrm{N}=75, \mathrm{r}_{\mathrm{s}}=-.11, \mathrm{p}=.33 ; \mathrm{N}=43, \mathrm{r}_{\mathrm{s}}=-.08, \mathrm{p}=.63\right)$, or proportion hesitations $\left(\mathrm{N}=75, \mathrm{r}_{\mathrm{s}}=-.03\right.$, $\left.527 \mathrm{p}=.83 ; \mathrm{N}=43, \mathrm{r}_{\mathrm{s}}=.007, \mathrm{p}=.97\right)$ (Bonferroni correction, $\mathrm{p}<.0125,4$ comparisons per subject group). 528 In general, these results support a relationship between language fluency variables and gesture rate 529 during the Sandwich task, which may be in large part driven by viewpoint gesture rate.

530 We then evaluated the relationship between gesture rate and language variables during the 531 Window task, finding a significant correlation with words per minute [only for matched group] $532\left(\mathrm{~N}=75, \mathrm{r}_{\mathrm{s}}=-.19, \mathrm{p}=.097 ; \mathrm{N}=43, \mathrm{r}_{\mathrm{s}}=-.54, \mathrm{p}<.001\right)$ and total utterances [only for large group] $(\mathrm{N}=75$, 
$533 \mathrm{r}_{\mathrm{s}}=.34, \mathrm{p}=.003 ; \mathrm{N}=43, \mathrm{r}_{\mathrm{s}}=-.04, \mathrm{p}=.82$ ) (Bonferroni correction, $\mathrm{p}<.0125,4$ comparisons per subject

534 group). We did not identify a significant relationship with speaking time $\left(\mathrm{N}=75, \mathrm{r}_{\mathrm{s}}=.24, \mathrm{p}=.04\right.$;

$\left.535 \mathrm{~N}=43, \mathrm{r}_{\mathrm{s}}=-.01, \mathrm{p}=.94\right)$ or proportion hesitations $\left(\mathrm{N}=75, \mathrm{r}_{\mathrm{s}}=-.03, \mathrm{p}=.82 ; \mathrm{N}=43, \mathrm{r}_{\mathrm{s}}=.32, \mathrm{p}=.03\right)$

536 (Bonferroni correction, $\mathrm{p}<.0125,4$ comparisons per subject group). Exploratory analyses

537 demonstrated that viewpoint gesture rate during Window did not significantly associate with

538 speaking duration $\left(\mathrm{N}=75, \mathrm{r}_{\mathrm{s}}=.06, \mathrm{p}=.62 ; \mathrm{N}=43, \mathrm{r}_{\mathrm{s}}=-.04, \mathrm{p}=.79\right)$ or total utterances $\left(\mathrm{N}=75, \mathrm{r}_{\mathrm{s}}=.21\right.$,

$539 \mathrm{p}=.07 ; \mathrm{N}=43, \mathrm{r}_{\mathrm{s}}=-.06, \mathrm{p}=.70$ ), but was significantly related to language fluency in the matched

540 group for words per minute $\left(\mathrm{N}=75, \mathrm{r}_{\mathrm{s}}=-.07, \mathrm{p}=.53 ; \mathrm{N}=43, \mathrm{r}_{\mathrm{s}}=-.37, \mathrm{p}=.013\right)$ and proportion

541 hesitations $\left(\mathrm{N}=75, \mathrm{r}_{\mathrm{s}}=.06, \mathrm{p}=.63 ; \mathrm{N}=43, \mathrm{r}_{\mathrm{s}}=.37, \mathrm{p}=.01\right)$ (Bonferroni correction, $\mathrm{p}<.0125,4$

542 comparisons per subject group). This pattern was similar for referential + metaphoric gesture rate,

543 which did not significantly associate with speaking duration $\left(\mathrm{N}=75, \mathrm{r}_{\mathrm{s}}=.12, \mathrm{p}=.29 ; \mathrm{N}=43, \mathrm{r}_{\mathrm{s}}=.02\right.$,

$544 \mathrm{p}=.91)$ or words per minute $\left(\mathrm{N}=75, \mathrm{r}_{\mathrm{s}}=.02, \mathrm{p}=.84 ; \mathrm{N}=43, \mathrm{r}_{\mathrm{s}}=-.19, \mathrm{p}=.23\right)$ but which approached a

545 significant relationship with total utterances $\left(\mathrm{N}=75, \mathrm{r}_{\mathrm{s}}=.27, \mathrm{p}=.02 ; \mathrm{N}=43, \mathrm{r}_{\mathrm{s}}=.04, \mathrm{p}=.79\right)$ and was

546 significantly related to proportion hesitations [whole group only] $\left(\mathrm{N}=75, \mathrm{r}_{\mathrm{s}}=-.27, \mathrm{p}=.019 ; \mathrm{N}=43\right.$,

$547 \mathrm{r}_{\mathrm{s}}=-.24, \mathrm{p}=.13$ ) (Bonferroni correction, $\mathrm{p}<.0125,4$ comparisons per subject group). Therefore, it

548 appears that gesture rate's relationship with language may be influenced by both types of iconic 549 gesture.

550 Globally, these results support a relationship between iconic gesturing rate and speech, 551 with some task specificity: a relationship of gesture rate with speech fluency in the Sandwich task, 552 and with both speech fluency and gross speech output in the Window task.

\section{Relationship of Iconic Gesture with Extra-task Fluency}

554 As a complementary analysis to evaluate language fluency, we evaluated the relationship

555 of iconic gesture with an extra-task metric of spoken language fluency by evaluating iconic gesture 
use in three fluency groups (from the large group [N=75] and matched group [N=43]) derived from

557 a standardized aphasia battery: low fluency ( $\mathrm{N}=75$ group, 22 subjects; $\mathrm{N}=43$ group, 12 subjects),

558 fluent with errors ( $\mathrm{N}=75$ group, 21 subjects; $\mathrm{N}=43$ group, 13 subjects), and high functional fluency

559 ( $\mathrm{N}=75$ group, 32 subjects; $\mathrm{N}=43$ group, 18 subjects). To do so, we computed Kruskal-Wallis $\mathrm{H}$

560 tests of independent samples (sometimes also called the "one-way ANOVA on ranks"), evaluating

561 significant differences in gesture rate and frequency by fluency group per task (corrected at

562 Bonferroni, $\mathrm{p}<.025,2$ comparisons per subject group). Note that fluency groups did not

563 significantly differ by age $(\mathrm{N}=75, \mathrm{H}=.88, \mathrm{p}=.65 ; \mathrm{N}=43, \mathrm{H}=.14, \mathrm{p}=.93)$, though did significantly

564 differ by aphasia duration in the large subject group $(\mathrm{N}=75, \mathrm{H}=7.59, \mathrm{p}=.02 ; \mathrm{N}=43, \mathrm{H}=5.57, \mathrm{p}=.06)$

565 (corrected at Bonferroni, $\mathrm{p}<.025,2$ comparisons per subject group).

\section{Gesture Frequency's Relationship with Fluency Group.}

We did not identify a significant fluency group effect on iconic gesture frequency for either

568 Window $(\mathrm{N}=75, \mathrm{H}=.32, \mathrm{p}=.85 ; \mathrm{N}=43, \mathrm{H}=4.76, \mathrm{p}=.09)$ or Sandwich $(\mathrm{N}=75, \mathrm{H}=5.09, \mathrm{p}=.08 ; \mathrm{N}=43$,

$569 \mathrm{H}=4.64, \mathrm{p}=.10)$ (corrected at Bonferroni, $\mathrm{p}<.025,2$ comparisons per subject group).

570 As an exploratory analysis, we looked at the relationship between fluency groups and 571 iconic gesture type frequency (viewpoint, referential + metaphoric) by task. For the Window task, 572 we did not identify a significant effect of fluency group on referential + metaphoric gesture $(\mathrm{N}=75$, $573 \mathrm{H}=.015, \mathrm{p}=.99 ; \mathrm{N}=43, \mathrm{H}=.33, \mathrm{p}=.85)$ or viewpoint gesture $(\mathrm{N}=75, \mathrm{H}=.46, \mathrm{p}=.79 ; \mathrm{N}=43, \mathrm{H}=2.41$, $574 \mathrm{p}=.30$ ) (corrected at Bonferroni, $\mathrm{p}<.025,2$ comparisons per subject group). For the Sandwich task, 575 there was no effect (whole group) yet a significant effect (matched group) of fluency group on 576 referential + metaphoric gesture frequency $(\mathrm{N}=75, \mathrm{H}=5.43, \mathrm{p}=.066 ; \mathrm{N}=43, \mathrm{H}=7.74, \mathrm{p}=.021)$, but 577 no significant effect of fluency group was identified for viewpoint gesture frequency $(\mathrm{N}=75$, $578 \mathrm{H}=.496, \mathrm{p}=.78 ; \mathrm{N}=43, \mathrm{H}=.895, \mathrm{p}=.64)$ (corrected at Bonferroni, $\mathrm{p}<.025,2$ comparisons per subject 
group). Pairwise comparisons corrected at Bonferroni $\mathrm{p}<.017$ (3 comparisons) for the referential

$580+$ metaphoric gestures made during the Sandwich task by the matched group $(\mathrm{N}=43)$ demonstrated

581 that this effect was driven by a difference between low fluency and high functional fluency groups

$582(\mathrm{p}=.029)$, where the low fluency group produced significantly more referential + metaphoric

583 gestures. The fluent with errors and the high functional fluency group did not differ significantly

584 on referential + metaphoric gestures produced during Sandwich $(p=.14)$, and nor did the low and

585 fluent with errors differ significantly on referential + metaphoric gestures $(\mathrm{p}>.99)$. Therefore,

586 results suggest that referential + metaphoric gestures, more than viewpoint gesture frequency or

587 total iconic gesture frequency, were produced significantly more often by the low fluency group

588 during the Sandwich task.

\section{Gesture Rate's Relationship with Fluency Group.}

We identified a significant difference in gesture rate by fluency group during the Window $\operatorname{task}(\mathrm{N}=75, \mathrm{H}=2.30, \mathrm{p}=.32 ; \mathrm{N}=43, \mathrm{H}=15.14, \mathrm{p}=.001)$ and Sandwich task $(\mathrm{N}=75, \mathrm{H}=5.98, \mathrm{p}=.05$;

$592 \mathrm{~N}=43, \mathrm{H}=8.63, \mathrm{p}=.013$ ). Note that, for both tasks, only the $\mathrm{N}=43$ group showed a significant 593 relationship between fluency group and gesture rate, thus post hoc pairwise comparisons were 594 done only for this group. Pairwise comparisons (corrected at Bonferroni $\mathrm{p}<.017,3$ comparisons) 595 for gesture rate by fluency group on the Window task demonstrated a significantly higher gesture 596 rate in the low fluency group compared with the fluent with errors group $(\mathrm{p}=.001)$, and high 597 functional fluency group $(\mathrm{p}<.001)$ (Figure 2, top). There was not a significant difference between 598 the fluent with errors and high functional fluency groups $(p=.84)$. Exploration of pairwise 599 comparisons (corrected at Bonferroni $\mathrm{p}<.017,3$ comparisons) for gesture rate by fluency group on 600 the Sandwich task demonstrated the same pattern, with the low fluency group producing a 601 significantly higher gesture rate compared with the fluent with errors group $(\mathrm{p}=.012)$ and compared 
602 with the high functional fluency group $(\mathrm{p}=.008)$ (Figure 2, bottom). Again, there was not a 603 significant difference between the fluent with errors and high functional fluency groups $(\mathrm{p}=.98)$. 604 Altogether, these results demonstrate that the low fluency group produced more gestures per word. 605 We then conducted exploratory analyses to evaluate the relationship between the fluency 606 groups and gesture rate by gesture type (viewpoint, referential + metaphoric) and task. We did not 607 identify a significant difference between fluency groups in rate of referential + metaphoric 608 gestures, for either Window $(\mathrm{N}=75, \mathrm{H}=.21, \mathrm{p}=.90 ; \mathrm{N}=43, \mathrm{H}=2.25, \mathrm{p}=.33)$ or Sandwich $(\mathrm{N}=75$, $609 \mathrm{H}=1.26, \mathrm{p}=.53 ; \mathrm{N}=43, \mathrm{H}=.43, \mathrm{p}=.81)$ tasks. We identified a significant difference between fluency 610 groups in the rate of viewpoint gestures produced during the Window task for the matched group $611(\mathrm{~N}=75, \mathrm{H}=2.29, \mathrm{p}=.32 ; \mathrm{N}=43, \mathrm{H}=9.04, \mathrm{p}=.01)$ but for neither subject group during the Sandwich 612 task $(\mathrm{N}=75, \mathrm{H}=3.84, \mathrm{p}=.15 ; \mathrm{N}=43, \mathrm{H}=5.19, \mathrm{p}=.08)$ (corrected at Bonferroni, $\mathrm{p}<.025,2$ 613 comparisons per subject group). Pairwise comparisons evaluating the rate of viewpoint gestures 614 produced during the Window task for the matched group (corrected at Bonferroni $\mathrm{p}<.017,3$ 615 comparisons) showed significant differences between the low fluency group and the fluent with 616 errors group ( $\mathrm{p}=.01)$ and between the low fluency group and the high functional fluency group $617(\mathrm{p}=.006)$. In both cases, the low fluency group demonstrated a higher viewpoint gesture rate during 618 Window. There was not a significant difference between the fluent with errors and the high 619 functional fluency group $(\mathrm{p}=.96)$.

620 In summary, total iconic gesture rate was higher in persons from the low fluency group, 621 and when looking specifically at rates of gesture types, this seemed to be driven by the viewpoint 622 gesture, particularly in the Window task. 


\section{Discussion}

We evaluated the relationship of iconic gesturing with demographic, language, and task

627 variables in a large group of persons with post-stroke, chronic aphasia (PWA). Below, we will

628 discuss how these results fit in within overarching, theoretical hypotheses of gesture, as well as

629 prior findings of iconic gesture usage in aphasia. We will end with discussing clinical implications

630 of this work.

Regarding demographic correlates of iconic gesture use, aphasia chronicity was correlated

632 with iconic gesture usage, and this correlation was driven by iconic gesture frequency produced

633 during the Window task. That is, those individuals who were living with aphasia for a longer period

634 of time were those who tended to use a higher frequency of iconic gestures during the Window

635 task. Generally, this may speak to gestures serving as a compensatory, or supportive, addition to

636 their spontaneous speech (Dipper et al., 2015). But, more specifically, we identified a significant

637 relationship with aphasia duration only in the Window task and not the Sandwich task, which may

638 suggest an interaction of task demands, aphasia duration, and iconic gesture use. Further evaluation

639 directly contrasting more tasks of varying types (e.g., narrative, procedural, expository,

640 descriptive), and cognitive and linguistic demands (e.g., visual aid, verbal working memory use,

641 semantic memory use, episodic memory use) will enhance our understanding of this possible,

642 clinically-relevant interaction. As we do not yet understand the extent to which iconic gesture use

643 changes over time - there is a paucity of longitudinal studies on iconic gesture in aphasia recovery

644 (Braddock, 2007) - cross sectional designs such as the one suggested may facilitate hypothesis

645 creation for future, longitudinal designs.

646 Notably, we did not identify a significant relationship between aphasia severity and iconic

647 gesture frequency, which complements prior research, which identified a relationship between 
648 aphasia severity and concrete deictic gestures but not iconic gestures (Sekine \& Rose, 2013b). That

649 is, severe aphasia does not preclude iconic gesture use, which has clinical ramifications for

650 assessment of gesture and treatment utilizing gesture as a predominant or complementary

651 communicative modality (Rose et al., 2013).

652 Innovatively, we evaluated the main effect of task on iconic gesture in aphasia. Task has

653 been shown to influence spoken language in persons with and without aphasia (Dalton \&

654 Richardson, 2019; Fergadiotis et al., 2011; Fergadiotis \& Wright, 2011; Li et al., 1996; Shadden

655 et al., 1990; Stark, 2019a; Ulatowska et al., 1981; Wright \& Capilouto, 2009) and it is perhaps not

656 surprising that we identified a main effect of task on iconic gesture frequency and rate in our

657 subject group of persons with aphasia. Specifically, subjects produced statistically more iconic

658 gestures, and gestured at a greater rate, during the procedural narrative task (Sandwich) than during

659 the picture sequence, expositional task (Window). There is a tradition in the gesture literature to

660 use procedural tasks to evaluate gesture, especially in clinical samples (Cocks et al., 2007;

661 Hilverman et al., 2016b; Pritchard et al., 2015) and our current work underscores this trend, as the

662 procedural task (Sandwich) tended to associate with more iconic gestures and a higher gesture.

663 One explanation for the difference in iconic gesture production by task is shared knowledge

664 (or common ground). That is - one task, the picture sequence task - provided a visual cue that was

665 available to both the primary speaker and the other interlocutor (i.e., experimenter). Because the

666 picture sequence was available to both persons in the experiment room, it may have been the case

667 that fewer iconic gestures were produced because of shared knowledge (Bottenberg \& Lemme,

668 1991; Campisi \& özyürek, 2013; but see, Brenneise-Sarshad et al., 1991). Additionally, gestures

669 tend to be smaller (Hoetjes et al., 2015; Kuhlen et al., 2012) and lower in the visual field (Hilliard

$670 \&$ Cook, 2016) when sharing common ground. In the case of a shared visual cue, iconic gestures 
671 may not have been favored by either subject group because of a reliance on other types of gestures

672 - specifically, concrete deictic gestures (Sekine \& Rose, 2013b). Whilst we did not report on other

673 gestures produced during these tasks here, as we wanted to focus on iconic gesture usage, we did

674 collect data on concrete deictic (e.g., pointing) gestures, finding that many gestures produced by

675 the aphasia group included pointing to specific parts of the Window picture (Table S2). We

676 postulated earlier, in the introduction, that iconic gesturing may be used more often, and with a

677 greater success rate, when tasks do not involve other visual stimuli (e.g., picture descriptions), as

678 they stand in for the concrete imagery that may otherwise facilitate lexical access. It may likewise

679 be that the presence of a visual support systematically varied task demands. For example, the

680 picture may constrain what the participants said, and also decrease memory demands. Prior work

681 demonstrates that rich episodic detail gives rise to more gestures (Hilverman et al., 2016a). Finally,

682 the Sandwich task may have employed more spatial words and imagery given its procedural

683 nature; iconic gesture frequency has been shown to positively correlate with lexical items related

684 to space and movement (Atit et al., 2013; Hostetter \& Alibali, 2019; Kita \& Lausberg, 2008;

685 Pritchard et al., 2015). Therefore, it may be the case that these two tasks are not directly

686 comparable because of cognitive demands and task constraint, but results do seem to support the

687 notion that more iconic gestures, at a greater rate, are produced during a narrative where no visual

688 aids are present, which complements prior evidence.

For our second research question, we evaluated the relationship between spoken language

690 and iconic gesture. There are a variety of theories exploring the relationship between spoken

691 language and iconic gesture. These theories hypothesize, respectively, that gestures are used more

692 frequently when spoken language production is made more difficult, or otherwise impaired (de

693 Ruiter, 2006; McNeill, 1992) and that using gestures facilitate lexical retrieval (Krauss, 1998). 
694 Because of the main effect of task, we evaluated relationships between iconic gesture and language

695 by task. During the Window task, we did not identify a significant relationship between language

696 variables and iconic gesture frequency, but did identify a relationship between iconic gesture rate

697 and speaking rate. Specifically, with increasing speaking rate during the Window task, we

698 observed a reduced gesture rate. This finding is complementary to the result that the low fluency

699 group (recall, a group identified as low fluency from a standardized testing battery) produced

700 significantly higher rates of iconic gestures during Window. That is, we identified that iconic

701 gesture rate during the Window task associated with two metrics of dysfluency, one task-specific

702 and one extra-task (standardized battery), together denoting that, at least for this task and its

703 cognitive-linguistic demands, gesture rate was strongly, negatively related to spoken language

704 fluency. During the Sandwich task, we identified a significant relationship between gross language

705 and iconic gesture frequency, such that more iconic gestures were produced alongside longer

706 speaking times and long utterances. The positive correlation between gross language and iconic

707 gesture frequency in the Sandwich task may reflected increased task demands (e.g., no visual

708 material available, limited common ground), culminating in more gestures produced. In regards to

709 the relationship of iconic gesture with dysfluency during the Sandwich task, gesture rate

710 approached a significant relationship with task-specific metrics of fluency (speaking rate,

711 hesitations), and was significantly related to extra-task fluency (from standardized testing battery),

712 complementing the profile shown in the Window results.

713 Together, these results support an overall relationship between iconic gesture rate and spoken

714 language, especially fluency, which lends support for hypotheses related to shared pre-conceptual

715 space for gesture and speech, as well as for a role of iconic gesture in enhancing lexical retrieval.

716 It should be noted that most metrics of fluency are influenced by measures of grammatical 
717 competence, lexical retrieval, and speech production, or a combination of these linguistic processes

718 (Gordon \& Clough, 2020), which speaks to the complexity of identifying the extent to which iconic

719 gesture (for example) influences each linguistic process (e.g., grammatical competence, lexical

720 retrieval, speech production). This work enhances prior work evaluating fluency based on aphasia

721 types (e.g., non-fluent vs fluent, Broca's vs. Wernicke's) by evaluating task-specific linguistic

722 information as well as a standardized metric of spoken language fluency. Sekine \& Rose (2013b)

723 correlated the Spontaneous Speech Fluency score (a composite score of the Fluency score

724 described here, in addition to an Informational Content score), with iconic gesture frequency in

725 their sample of persons with aphasia during a story retell narrative, finding a small-medium,

726 significant, negative correlation between gesture frequency and Spontaneous Speech Fluency

727 score. Their sample was larger, which may have contributed to improved power and identification

728 of a small-medium relationship between an extra-task metric of fluency and iconic gesture

729 frequency. Recall that we did not identify a relationship between gesture frequency and Fluency

730 score. Note, too, that Sekine \& Rose (2013b) did not evaluate the relationship between gesture rate

731 and their metric of fluency, however. It should be noted that there is some difference in these

732 comparisons. We chose the Fluency score - rather than the Spontaneous Speech Fluency score -

733 because the former did not incorporate Informational Content. Informational Content score speaks

734 more to the communication / functional value of the speech than the fluency, and the Informational

735 Content score is typically highly related to the overall aphasia severity (Kertesz, 2007). Despite

736 nuances, there is a clear relationship between iconic gesture (be it frequency or rate) and spoken

737 language fluency.

738 Therefore, there is mounting evidence that discourse task affects spontaneous iconic gesture

739 usage in persons with and without aphasia. We provide one of the few studies directly contrasting 
740 iconic gesture usage across two tasks in the same group of subjects, with hope that more work

741 follows our own in exploring these task-specific gesture relationships. Exploring task-specific

742 gesture relationships across all gesture types (i.e., along Kendon's continuum) gets at a more

743 naturalistic evaluation of gesture, which allows us to jump from highly constrained experimental

744 investigations of gesture to more naturalistic evaluation of gesture. While the main purpose of the

745 current study was to look at task-related differences in iconic gesturing, Table S2 makes clear that

746 there are likely other task-related differences in other types of gestures (e.g., concrete deictic), and

747 a future, multivariate investigation of the relationship between task and gesture type would be

748 highly valuable in determining typical spontaneous gesture patterns in persons with aphasia.

749 We did not evaluate the informational relationship of each of iconic gestures to their respective

750 speech (i.e., to disambiguate, to add information, to be redundant), but further evaluation of the

751 informational relationship between speech and iconic gesture type is necessary to better understand

752 the possible task-specific facilitatory effects of each iconic gesture type. The informational

753 relationship of gesture with speech may also differ by aphasia type. In one study, people with non-

754 fluent aphasia primarily used gesture to replace verbal communication whilst those with fluent

755 aphasia used gesture redundantly with verbal communication (Behrmann \& Penn, 1984). In

756 another study, different patterns of gesture use in a Broca's aphasia group, Wernicke's aphasia

757 group, and neurotypical control group showed that gesture played a dominate role in enhancing

758 communication, rather than facilitating lexical retrieval, among the speakers with aphasia (Kong

759 et al., 2017). Note that these studies did not constrain their evaluation of gesture to iconic gesture.

760 Further, evaluation of other important metrics describing the relationship between gesture and

761 speech, such as temporal ordering (Hadar et al., 1998a; Hadar \& Butterworth, 1997), will elucidate

762 task effects on iconic gesturing. 
Future work should focus on how task-specific, and extra-task linguistic ability, predict

764 iconic gesture usage, and how that differs according to task demands. Doing so can provide

765 evidence about the level of breakdown in the language system in aphasia. Rose \& Douglas (2001)

766 explored this in reference to gesture's facilitatory effects in object naming, finding that individuals

767 with phonological access, storage, or encoding difficulties showed improved naming abilities

768 when iconic gestures were present, versus those with a semantic impairment or a motor speech

769 disorder (e.g., apraxia of speech). Complementary work evaluating a wordless cartoon retelling in

770 a single case study of a person with conduction aphasia, who had difficulties with phonological

771 encoding, demonstrated production of meaningful iconic gestures, suggesting an intact pre-

772 linguistic conceptual as well as semantic system (Cocks et al., 2011). Further, it may be damage

773 to the very earliest part of speech production - pre-linguistic conceptualization - that predicts the

774 use, informativeness, and correctness of iconic gestures. Persons with aphasia and concomitant

775 pre-linguistic conceptual impairments (e.g., non-verbal design copying, spatial rotation

776 mentalization) have been shown to produce gestures less frequently than those with relatively

777 intact conceptual abilities (Hadar et al., 1998), further suggesting that it is the pre-linguistic

778 conceptualization that is critical for gesturing (especially iconic). Unfortunately, we could not

779 stratify iconic gesture use by pre-linguistic conceptual ability in the current dataset, as the

780 AphasiaBank corpus does not provide this data. There are additional future avenues that would be

781 fruitful: as Clough \& Duff (2020) note, no experimental studies in aphasia have examined how

782 encouraging or constraining gesture affects the fluency of verbal output, or indeed, whether listener

783 perceptions of fluency are influenced by gesture use. Creating a comprehensive picture in regards

784 to the impact of gesturing on fluency in aphasia, by also taking into account different tasks and the

785 use of encouraging or restraining gesture, will be a valuable addition to the current literature. 
Interestingly, while gesture has a considerable role in multimodal communication and

787 countless studies have demonstrated increased gesture use by persons living with aphasia, gesture

788 has received comparatively little focus in the speech-language therapy literature, with mixed

789 evidence for its use as a part of (or standalone) therapy (Rose et al., 2013). One such reason for

790 the relatively limited scope of studies evaluating gesture therapy is a school of thought that co-

791 speech gesturing in persons living with aphasia may inhibit linguistic productivity (e.g.,

792 Constraint-Induced Language Theory; Cherney et al., 2008). Nonetheless, there remains a decisive

793 issue in the aphasia therapy literature: whilst evidence supports the use of behavioral therapy to

794 improve aphasia, the mechanisms of therapy that promote change remain unclear (Brady et al.,

795 2016). The review by Rose et al. (2013) emphasizes that gestures should be included in clinical

796 assessments in aphasia, and a recent review by Clough \& Duff (2020) further emphasizes that a

797 potent means of better understanding the mechanisms of successful behavioral therapy is to

798 comprehensively evaluate multimodal communication (i.e., gesture alongside written and spoken

799 language) in persons with neurogenic communication disorders.

800 In sum, we need to better understand how and when spontaneous gestures are used,

801 language system characteristics that associate with specific types of gestures (i.e., intact pre-

802 linguistic semantic ability and iconic gesture usage), how gestures differ across tasks and

803 communication scenarios, and the informational and temporal relationship between gesture and

804 speech. A lot of work has been done to clarify spontaneous gesture frequency in aphasia (de Ruiter,

805 2006; Dipper et al., 2011, 2015; Hogrefe et al., 2016; Kistner et al., 2019; Krauss \& Hadar, 2001;

806 Pritchard et al., 2013; Rose et al., 2017; Scharp et al., 2007; Sekine \& Rose, 2013b), with Clough

$807 \&$ Duff (2020)'s recent review detailing this, but an enhanced investigation of the role of gesture

808 in spontaneous speech - especially across more naturalistic elicitation methods - is both under- 
researched and necessary to comprehensively understand the role of gesture in a variety of

810 naturalistic situations. A comprehensive evaluation of gesture should ideally comprise tasks

811 spanning the cognitive and linguistic spectra: constrained tasks (e.g., ask a person to demonstrate,

812 with gesture, how to use a picture object or perform a pictured action), semi-constrained tasks

813 (e.g., structured discourse tasks provided here, where there are clear, structured instructions and,

814 in one case, imagery), and unstructured tasks (e.g., observation of gesture use in conversation with

815 a trusted conversation partner).

\section{Limitations}

817 We acknowledge limitations in the current study. Limb apraxia (and other forms of apraxia, i.e.,

818 ideational, ideomotor) data is not available in AphasiaBank, and we therefore could not evaluate

819 the extent to which apraxia influenced iconic gesture frequency or rate during each task (Borod et

820 al., 1989). This study was not pre-registered, but future studies mining databases such as

821 AphasiaBank should consider pre-registration to improve replicability and reliability of proposed

822 analyses. The AphasiaBank sample, while large, is not representative across aphasia (e.g., no

823 global or isolation aphasia in this sample). The AphasiaBank sample includes only those with

824 chronic aphasia (in some cases, many years post-stroke), and therefore the conclusions drawn in

825 this study may not apply to those with more acute or subacute aphasia. Finally, AphasiaBank is a

826 rich resource for studying discourse in aphasia, and has been leading the way in advocating for

827 increased rigor in spoken language discourse analysis in aphasia - however, we did have to exclude

828 participants because of video camera angle, and in almost all scenarios (because of the

829 experimental tasks), there was a table present directly in front of the speaker, which has been

830 shown to greatly constrain gesture usage because of the availability of the table on which to rest

831 the hands and make gesture coding (e.g., differentiation into unique strokes) difficult (Jacobs \& 
832 Garnham, 2007). Future work in gesture and multimodal communication work should apply the 833 same methodological rigor to the study of gesture that we do to speech, taking into consideration 834 some of these critical components (e.g., room and video set-up). A final limitation was that we 835 chose to code referential and metaphoric gestures as a single category (referential + metaphoric), 836 which did not allow us to evaluate the differences in referential and metaphoric gestures by task. 837 Future work should evaluate differences between metaphoric and referential gesture usage in PWA 838 across task types. 
840 We would like to acknowledge Rachel Andros and Sarah Moats for their help with gesture rating. 


\section{References}

841 Atit, K., Göksun, T., Ormand, C. J., Manduca, C. A., Resnick, I., Shipley, T. F., \& Tikoff, B.

842 (2013). Spatial gestures point the way: A broader understanding of the gestural referent.

843 Proceedings of the 35th Annual Meeting of the Cognitive Science Society, 1786-1791.

844 Behrmann, M., \& Penn, C. (1984). Non-verbal communication of aphasic patients. British Journal of Disorders of Communication, 15, 16, https://www.researchgate.net/publication/16718129

Borod, J. C., Fitzpatrick, P. M., Helm-Estabrooks, N., \& Goodglass, H. (1989). The relationship between limb apraxia and the spontaneous use of communicative gesture in aphasia. Brain and Cognition, 10(1), 121-131. https://doi.org/10.1016/0278-2626(89)90079-1

850 Bottenberg, D., \& Lemme, M. (1991). Effect of shared and unshared listener knowledge on narratives of normal and aphasic adults.

Braddock, B. A. (2007). Links between language, gesture and motor skill: A longitudinal study of communication recovery in Broca's aphasia. Univ. Missouri-Columbia.

854 Brady, M., Kelly, H., Godwin, J., Enderby, P., \& Campbell, P. (2016). Speech and language therapy for aphasia following stroke. Cochrane Database of Systematic Reviews, 6.

857 Brenneise-Sarshad, R., Nicholas, L. E., \& Brookshire, R. H. (1991). Effects of Apparent Listener https://doi.org/10.1002/14651858.CD000425.pub4.www.cochranelibrary.com

Brookshire, R., \& Nicholas, L. (1994). Speech sample-size and test-retest stability of connected 
Research, 37(2), 399-407.

864 Campisi, E., \& özyürek, A. (2013). Iconicity as a communicative strategy: Recipient design in multimodal demonstrations for adults and children. Journal of Pragmatics, 47(1), 14-27.

Carlomagno, S., \& Cristilli, C. (2006). Semantic attributes of iconic gestures in fluent and nonfluent aphasic adults. Brain and Language, 99(1-2), 104-105. https://doi.org/10.1016/j.band1.2006.06.061

Cherney, L. R., Patterson, J. P., Raymer, A., Frymark, T., \& Schooling, T. (2008). Evidence-based systematic review: effects of intensity of treatment and constraint-induced language therapy for individuals with stroke-induced aphasia. Journal of Speech, Language, and Hearing Research, 51(5), 1282-1299. https://doi.org/10.1044/1092-4388(2008/07-0206)

Church, R. B., \& Goldin-Meadow, S. (1986). The mismatch between gesture and speech as an

Cicone, M., Wapner, W., Foldi, N., Zurif, E., \& Gardner, H. (1979). The relation between gesture and language in aphasic communication. Brain and Language, 8(3), 324-349. https://doi.org/10.1016/0093-934X(79)90060-9

880 Clough, S., \& Duff, M. C. (2020). The Role of Gesture in Communication and Cognition: Implications for Understanding and Treating Neurogenic Communication Disorders. In 
Communication Disorders, 46(4), 423-436. https://doi.org/10.3109/13682822.2010.520813

887 Cocks, N., Hird, K., \& Kirsner, K. (2007). The relationship between right hemisphere damage and gesture in spontaneous discourse. Aphasiology, 21(3-4), 299-319. https://doi.org/10.1080/02687030600911393

Dalton, S. G., \& Richardson, J. D. (2019). A Large-Scale Comparison of Main Concept Production Speech-Language Pathology, 28, 293-320. https://doi.org/10.23641/asha

Dargue, N., Sweller, N., \& Jones, M. P. (2019). When our hands help us understand: A metaanalysis into the effects of gesture on comprehension. Psychological Bulletin, 145(8), 765784. https://doi.org/10.1037/bu10000202

de Beer, C., de Ruiter, J. P., Hielscher-Fastabend, M., \& Hogrefe, K. (2019). The Production of Gesture and Speech by People With Aphasia: Influence of Communicative Constraints. Journal of Speech, Language, and Hearing Research, 62(12), 4417-4432. https://doi.org/10.1044/2019_JSLHR-L-19-0020

903

de Ruiter, J. (2006). Can gesticulation help aphasic people speak, or rather, communicate? Advances in Speech Language Pathology, 8(2), 124-127. https://doi.org/10.1080/14417040600667285 Production of Referring Expressions: Investigating the Tradeoff Hypothesis. Topics in Cognitive Science, 4(2), 232-248. https://doi.org/10.1111/j.1756-8765.2012.01183.x

Dipper, L., Cocks, N., Rowe, M., \& Morgan, G. (2011). What can co-speech gestures in aphasia tell us about the relationship between language and gesture? Gesture, 11(2), 123-147. https://doi.org/10.1075/gest.11.2.02dip 
909 Dipper, L., Pritchard, M., Morgan, G., \& Cocks, N. (2015). The language-gesture connection:

910 Evidence from aphasia. Clinical Linguistics and Phonetics, 29(8-10), 748-763.

$911 \quad$ https://doi.org/10.3109/02699206.2015.1036462

912 Fergadiotis, G., \& Wright, H. (2011). Lexical diversity for adults with and without aphasia across

913 discourse elicitation tasks. Aphasiology, 25(11), 1414-1430. https://doi.org/10.1007/s11103-

$914 \quad$ 011-9767-z.Plastid

915 Fergadiotis, G., Wright, H. H., \& Capilouto, G. J. (2011). Productive vocabulary across discourse

916 types. Aphasiology, 25(10), 1261-1278. https://doi.org/10.1080/02687038.2011.606974

917 Feyereisen, P. (1983). MANUAL ACTIVITY DURING SPEAKING IN APHASIC SUBJECTS. International Journal of Psychology, 18(1-4), 545-556.

919 https://doi.org/10.1080/00207598308247500

920 Goldblum, M. C. (1978). Les troubles des gestes d'accompagnement du langage au cours des 921 lesions corticales unilaterales. Du Contrôle Moteur à l'organisation Du Geste, 383-395.

922 Goldin-Meadow, S., \& Alibali, M. W. (2013). Gesture's Role in Speaking, Learning, and Creating 923 Language. Annual Review of Psychology, 64(1), 257-283. https://doi.org/10.1146/annurev$924 \quad$ psych-113011-143802

925 Gordon, J. K., \& Clough, S. (2020). How fluent? Part B. Underlying contributors to continuous 926 measures of fluency in aphasia. Aphasiology, 34(5), 643-663. $927 \quad$ https://doi.org/10.1080/02687038.2020.1712586

928 Graham, J. A., \& Heywood, S. (1975). The effects of elimination of hand gestures and of verbal 929 codability on speech performance. European Journal of Social Psychology, 5(2), 189-195. 930 https://doi.org/10.1002/ejsp.2420050204

931 Gullberg, M. (2006). Handling Discourse: Gestures, Reference Tracking, and Communication 

8333.2006.00344.x

934 Hadar, U., Wenkert-Olenik, D., Krauss, R., \& Soroker, N. (1998a). Gesture and the processing of 935 speech: Neuropsychological evidence. Brain and Language, 62(1), 107-126. https://doi.org/10.1006/brln.1997.1890

937 Hadar, U., Wenkert-Olenik, D., Krauss, R., \& Soroker, N. (1998b). Gesture and the processing of

Hadar, Uri. (1991). Speech-related body movement in aphasia: Period analysis of upper arms and speech: Neuropsychological evidence. Brain and Language, 62(1), 107-126.

Hadar, Uri, \& Butterworth, B. (1997). Iconic gestures, imagery, and word retrieval in speech. Semiotica, 115(1-2), 147-172. https://doi.org/10.1515/semi.1997.115.1-2.147

Hall, J. A., \& Gunnery, S. D. (2013). Gender differences in nonverbal communication. In J.A. Hall head movement. Brain and Language, 41(3), 339-366. https://doi.org/10.1016/0093$934 X(91) 90160-3$

Hilverman, C., Cook, S. W., \& Duff, M. C. (2016a). Hippocampal declarative memory supports Hilliard, C., \& Cook, S. W. (2016). Bridging gaps in common ground: Speakers design their gestures for their listeners. Journal of Experimental Psychology: Learning Memory and Cognition, 42(1), 91-103. https://doi.org/10.1037/xlm0000154 gesture production: Evidence from amnesia. Cortex, 85, 25-36. https://doi.org/10.1016/j.cortex.2016.09.015

Hilverman, C., Cook, S. W., \& Duff, M. C. (2016b). Hippocampal declarative memory supports 
gesture production: Evidence from amnesia. Cortex, 85, 25-36. https://doi.org/10.1016/j.cortex.2016.09.015

957 Hoetjes, M., Koolen, R., Goudbeek, M., Krahmer, E., \& Swerts, M. (2015). Reduction in gesture 958 during the production of repeated references. Journal of Memory and Language, 79-80, 117. https://doi.org/10.1016/j.jml.2014.10.004

960 Hogrefe, K., Rein, R., Skomroch, H., \& Lausberg, H. (2016). Co-speech hand movements during 961 narrations: What is the impact of right vs. left hemisphere brain damage? Neuropsychologia,

Holle, H., \& Gunter, T. C. (2007). The role of iconic gestures in speech disambiguation: ERP 93, 176-188. https://doi.org/10.1016/j.neuropsychologia.2016.10.015

Hostetter, A. B. (2011). When Do Gestures Communicate? A Meta-Analysis. Psychological Bulletin, 137(2), 297-315. https://doi.org/10.1037/a0022128

Hostetter, A. B., \& Alibali, M. W. (2019). Gesture as simulated action: Revisiting the framework. Psychonomic Bulletin and Review, 26(3), 721-752. https://doi.org/10.3758/s13423-018-

Jacobs, N., \& Garnham, A. (2007). The role of conversational hand gestures in a narrative task. Journal of Memory and Language, $56(2)$ 291-303. https://doi.org/10.1016/j.jml.2006.07.011

974 Kelly, S. D., Barr, D. J., Church, R. B., \& Lynch, K. (1999). Offering a Hand to Pragmatic 975 Understanding: The Role of Speech and Gesture in Comprehension and Memory. Journal of 976 Memory and Language, 40(4), 577-592. https://doi.org/10.1006/jmla.1999.2634

977 Kendon, A. (1980). Gesticulation and Speech: Two aspects of the process of utterance. In The 
Relationship of Verbal and Nonverbal Communication (pp. 207-227). De Gruyter. https://doi.org/10.1515/9783110813098.207

980

Kertesz, A. (2007). Western Aphasia Battery - Revised. The Psychological Corporation.

981

982

983

984

985

986

987

988

989

990

991

992

993

994

995

996

997

998

999

1000

Kistner, J., Dipper, L. T., \& Marshall, J. (2019). The use and function of gestures in word-finding difficulties in aphasia. Aphasiology, 33(11), 1372-1392. https://doi.org/10.1080/02687038.2018.1541343

Kita, S. (2014). Production of speech-accompanying gesture. In M. Goldrick, V. Ferreira, \& M. Miozzo (Eds.), The Oxford handbook of language production (pp. 451-459). Oxford University Press. https://psycnet.apa.org/record/2014-14212-027

Kita, Sotaro, \& Davies, T. S. (2009). Competing conceptual representations trigger co-speech representational gestures. Language and Cognitive Processes, 24(5), 761-775. https://doi.org/10.1080/01690960802327971

Kita, Sotaro, \& Lausberg, H. (2008). Generation of co-speech gestures based on spatial imagery from the right-hemisphere: Evidence from split-brain patients. Cortex, 44(2), 131-139. https://doi.org/10.1016/j.cortex.2006.04.001

Kong, A. P.-H., Law, S.-P., \& Chak, G. W.-C. (2017). A Comparison of Coverbal Gesture Use in Oral Discourse Among Speakers With Fluent and Nonfluent Aphasia. Journal of Speech, Language, and Hearing Research,60(7), 2031-2046. https://doi.org/10.1044/2017_JSLHRL-16-0093

Kong, A. P. H., Law, S. P., Wat, W. K. C., \& Lai, C. (2015a). Co-verbal gestures among speakers with aphasia: Influence of aphasia severity, linguistic and semantic skills, and hemiplegia on gesture employment in oral discourse. Journal of Communication Disorders, 56, 88-102. https://doi.org/10.1016/j.jcomdis.2015.06.007 
1001 Kong, A. P. H., Law, S. P., Wat, W. K. C., \& Lai, C. (2015b). Co-verbal gestures among speakers 1002 with aphasia: Influence of aphasia severity, linguistic and semantic skills, and hemiplegia on 1003 gesture employment in oral discourse. Journal of Communication Disorders, 56, 88-102. 1004 https://doi.org/10.1016/j.jcomdis.2015.06.007

1005 Krauss, R. M. (1998). Why do we gesture when we speak? Current Directions in Psychological 1006 Science.

1007 Krauss, R. M., \& Hadar, U. (2001). The role of speech-related arm/hand gestures in word retrieval. 1008 In R. Campbell \& L. Messing (Eds.), Gesture, Speech, and Sign (pp. 93-116). Oxford 1009 University Press. https://doi.org/10.1093/acprof:oso/9780198524519.003.0006

1010 Kuhlen, A. K., Galati, A., \& Brennano, S. E. (2012). Gesturing integrates top-down and bottom1011 up information: Joint effects of speakers' expectations and addressees' feedback. Language 1012 and Cognition, 4(1), 17-41. https://doi.org/10.1515/langcog-2012-0002

1013 Li, E. C., della Volpe, A., Ritterman, S., \& Williams, S. E. (1996). Variation in grammatic 1014 complexity across three types of discourse. Journal of Speech-Language Pathology and $1015 \quad$ Audiology, 20(3), 180-186.

1016 Luria, A. (1970). Traumatic aphasia: Its syndromes, psychology and treatment (Vol 5). Walter de 1017 Gruyter.

1018 MacWhinney, B. (2018). Tools for Analyzing Talk Part 2: The CLAN Program (Issue 2000). 1019 https://talkbank.org/manuals/CLAN.pdf\%0Ahttps://doi.org/10.21415/T5G10R

1020 MacWhinney, B., Forbes, M., \& Holland, A. (2011). AphasiaBank: Methods for Studying 1021 Discourse. Aphasiology, 25(11), $1286-1307$.

1022 https://doi.org/10.1080/02687038.2011.589893.AphasiaBank

1023 McNeill, D. (1992). Hand and mind: What gestures reveal about thought. University of Chicago 
Press.

1025 Menn, L., Reilly, K. F., Hayashi, M., Kamio, A., Fujita, I., \& Sasanuma, S. (1998). The Interaction 1026 of Preserved Pragmatics and Impaired Syntax in Japanese and English Aphasic Speech. Brain and Language, 61(2), 183-225. https://doi.org/10.1006/BRLN.1997.1838

1028 Morsella, E., \& Krauss, R. M. (2004). The role of gestures in spatial working memory and speech. 1029 American Journal of Psychology, 117(3), 411-424. https://doi.org/10.2307/4149008

1030 Pritchard, M., Cocks, N., \& Dipper, L. (2013). Iconic gesture in normal language and word

Pritchard, M., Dipper, L., Morgan, G., \& Cocks, N. (2015). Language and iconic gesture use in procedural discourse by speakers with aphasia. Aphasiology, 29(7), 37-41. https://doi.org/10.1080/02687038.2014.993912

1036 Rauscher, F. H., Krauss, R. M., \& Chen, Y. (1996). GESTURE, SPEECH, AND LEXICAL ACCESS: The Role of Lexical Movements in Speech Production. Psychological Science,

1039 Rose, M., \& Douglas, J. (2001). The differential facilitatory effects of gesture and visualisation 1040 processes on object naming in aphasia. Aphasiology, 15(10-11), 977-990. $1041 \quad$ https://doi.org/10.1080/02687040143000339

1042 Rose, M. L., Mok, Z., \& Sekine, K. (2017). Communicative effectiveness of pantomime gesture 1043 in people with aphasia. International Journal of Language and Communication Disorders, 1044 52(2), 227-237. https://doi.org/10.1111/1460-6984.12268

1045 Rose, M., Raymer, A., Lanyon, L., \& Attard, M. (2013). A systematic review of gesture treatments 1046 for post-stroke aphasia. Aphasiology, 27(9), $1090-1127$. 
https://doi.org/10.1080/02687038.2013.805726

1048 Scharp, V. L., Tompkins, C. A., \& Iverson, J. M. (2007). Gesture and aphasia: Helping hands?

1049 Aphasiology, 21(6-8), 717-725. https://doi.org/10.1080/02687030701192273

1050 Sekine, K., \& Rose, M. L. (2013a). The relationship of aphasia type and gesture production in 1051 people with aphasia. American Journal of Speech-Language Pathology, 22(4), 662-672. $1052 \quad$ https://doi.org/10.1044/1058-0360(2013/12-0030)

1053 Sekine, K., \& Rose, M. L. (2013b). The relationship of aphasia type and gesture production in 1054 people with aphasia. American Journal of Speech-Language Pathology, 22(4), 662-672. $1055 \quad$ https://doi.org/10.1044/1058-0360(2013/12-0030)

1056 Shadden, B. B., Burnette, R. B., Eikenberry, B. R., \& DiBrezzo, R. (1990). All discourse tasks are $1057 \quad$ not created equal.

1058 Stark, B. C. (2019a). A comparison of three discourse elicitation methods in aphasia and age1059 matched adults: Implications for language assessment and outcome. American Journal of 1060 Speech-Language Pathology, 28(3), 1067-1083. https://doi.org/10.1044/2019_AJSLP-18$1061 \quad 0265$

1062 Stark, B. C. (2019b). A comparison of three discourse elicitation methods in aphasia and age1063 matched adults: Implications for language assessment and outcome. American Journal of 1064 Speech-Language Pathology, 28(3). https://doi.org/10.1044/2019_AJSLP-18-0265

1065 Stark, B. C., \& Fukuyama, J. (2020). The effect of task: leveraging big data to understand spoken 1066 discourse in speakers with and without aphasia. Language, Cognition and Neuroscience, Dec. $1067 \quad$ https://doi.org/10.1080/23273798.2020.1862258

1068 Ulatowska, H. K., North, A. J., \& Macaluso-Haynes, S. (1981). Production of narrative and 1069 procedural discourse in aphasia. Brain and Language, 13(2), 345-371. 
https://doi.org/10.1016/0093-934X(81)90100-0

1071 Wright, H. H., \& Capilouto, G. J. (2009). Manipulating task instructions to change narrative 1072 discourse performance.

Aphasiology, 23(10), 1295-1308. https://doi.org/10.1080/02687030902826844 


\section{Supplementary}

Table S1. Iconic gesture examples from the gesture coding, for the Window task, and for the Sandwich task, demonstrating a variety of gesture forms used.

Table S2. Descriptive statistics of gesture type frequency for all gesture types (i.e., iconic, emblem, concrete deictic, and number) collected as a part of this study in $\mathrm{N}=75$ participants.

Table S3. Correlation table between demographic information, language information extracted from each discourse task, and iconic gestures (collapsed across subtypes; for frequency and rate) in $\mathrm{N}=75$ subjects.

Table S4. Correlation table between demographic information, language information extracted from each discourse task, and iconic gestures (collapsed across subtypes; for frequency and rate) in $\mathrm{N}=43$ subjects (subjects who gestured on both tasks). 


\section{Tables and Figures}

Table 1: Demographics of subject group $(\mathrm{N}=75)$.

\begin{tabular}{|c|c|}
\hline Demographics & M(SD) or Frequency \\
\hline Age (years) & $60.70(11.22)$ \\
\hline Education (years) & $15.43(2.58)$ \\
\hline "Aphasia Severity (WAB AQ)* & $73.73(14.37)$ \\
\hline Aphasia duration (years) & $5.01(4.31)$ \\
\hline Years of SLP therapy & $3.26(2.44)$ \\
\hline Race & $\begin{array}{l}8 \text { African American } \\
1 \text { Asian } \\
1 \text { Native Hawaiian or other Pacific Island } \\
62 \text { White } \\
\end{array}$ \\
\hline Ethnicity & 3 Hispanic or Latinx \\
\hline Gender^$^{\wedge}$ & 34 females \\
\hline Handedness (pre-morbid) & $\begin{array}{l}3 \text { ambidextrous } \\
7 \text { left-handed } \\
64 \text { right-handed } \\
1 \text { unknown }\end{array}$ \\
\hline Language Status & $\begin{array}{l}6 \text { childhood bilinguals (English plus } 2^{\text {nd }} \text { language by } 6 \text { years } \\
\text { old) } \\
6 \text { late bilinguals (English plus } 2^{\text {nd }} \text { language after } 6 \text { years } \\
\text { old) } \\
62 \text { monolinguals } \\
1 \text { multilingual (speaks } 3 \text { or more languages fluently) }\end{array}$ \\
\hline $\begin{array}{l}\text { Presence of dysarthria and/or apraxia of } \\
\text { speech }\end{array}$ & $\begin{array}{l}43 \text { with apraxia of speech } \\
8 \text { with dysarthria ( } 3 \text { unknown) }\end{array}$ \\
\hline Presence of hemiparesis or hemiplegia & $\begin{array}{l}23 \text { no motor impairment } \\
21 \text { right-sided hemiplegia (i.e., paralysis) } \\
28 \text { right-sided hemiparesis (i.e., weakness) } \\
2 \text { left-hemisphere hemiparesis (i.e., weakness) } \\
1 \text { unknown }\end{array}$ \\
\hline Aphasia etiology & 73 stroke, 2 other or unknown \\
\hline Types of aphasia & $\begin{array}{l}27 \text { Anomic } \\
19 \text { Broca's } \\
18 \text { Conduction } \\
0 \text { Global } \\
0 \text { Mixed Transcortical } \\
3 \text { Transcortical Motor } \\
1 \text { Transcortical Sensory } \\
2 \text { Wernicke's } \\
5 \text { Not Aphasic by WAB (i.e., scoring }>93.8 \text { on WAB) }\end{array}$ \\
\hline
\end{tabular}

WAB AQ = Western Aphasia Battery Aphasia Quotient

$\mathrm{SLP}=$ speech-language pathology

*=as measured by Western Aphasia Battery Revised Aphasia Quotient, where $100=$ no aphasia 
$\wedge=$ "gender" is the terminology used by AphasiaBank as of publication, but only two options were given to respondents: male or female. This therefore may not reflect other genders (e.g., non-binary, transgender) reflected in the dataset. 
Table 2: Descriptive statistics divided by task for full sample $(\mathrm{N}=75)$.

\begin{tabular}{|l|l|l|}
\hline Variable & \multicolumn{1}{|c|}{$\begin{array}{c}\text { Window Task } \\
\mathrm{M}(\mathrm{SD}, \text { range })\end{array}$} & \multicolumn{1}{|c|}{$\begin{array}{c}\text { Sandwich Task } \\
\mathrm{M}(\mathrm{SD}, \text { range })\end{array}$} \\
\hline $\mathrm{N}$ using at least 1 gesture & $43(57.3 \%)$ & $76(100 \%)$ \\
\hline Task duration (secs) & $54.51(37.33,10-228)$ & $44.96(29.00,5-140)$ \\
\hline Iconic gesture frequency & $1.84(2.59,0-11)$ & $7.11(4.39,1-34)$ \\
\hline Iconic gesture rate & $.03(.06,0-.27)$ & $.16(.09, .03-.41)$ \\
\hline
\end{tabular}


Table 3: Demographics for subgroup making an iconic gesture on both tasks $(\mathrm{N}=43)$.

\begin{tabular}{|c|c|}
\hline Demographics & M(SD) or Frequency \\
\hline Age (years) & $57.94(10.69)$ \\
\hline Education (years) & $15.62(2.53)$ \\
\hline Aphasia Severity (WAB AQ)* & $73.53(13.81)$ \\
\hline Aphasia duration (years) & $5.91(5.04)$ \\
\hline Years of SLP therapy & $3.59(2.69)$ \\
\hline Race & $\begin{array}{l}5 \text { African American } \\
1 \text { Asian } \\
1 \text { Native Hawaiian or other Pacific Island } \\
36 \text { White }\end{array}$ \\
\hline Ethnicity & 0 Hispanic or Latinx \\
\hline Gender $^{\wedge}$ & 21 females \\
\hline Handedness (pre-morbid) & $\begin{array}{l}3 \text { ambidextrous } \\
5 \text { left-handed } \\
34 \text { right-handed } \\
1 \text { unknown } \\
\end{array}$ \\
\hline Language Status & $\begin{array}{l}3 \text { childhood bilinguals (English plus } 2^{\text {nd }} \text { language by } 6 \text { years } \\
\text { old) } \\
5 \text { late bilinguals (English plus } 2^{\text {nd }} \text { language after } 6 \text { years } \\
\text { old) } \\
34 \text { monolinguals } \\
1 \text { multilingual (speaks } 3 \text { or more languages fluently) }\end{array}$ \\
\hline $\begin{array}{l}\text { Presence of dysarthria and/or apraxia of } \\
\text { speech }\end{array}$ & $\begin{array}{l}25 \text { with apraxia of speech } \\
3 \text { with dysarthria ( } 1 \text { unknown) }\end{array}$ \\
\hline Presence of hemiparesis or hemiplegia & $\begin{array}{l}11 \text { no motor impairment } \\
11 \text { right-sided hemiplegia (i.e., paralysis) } \\
19 \text { right-sided hemiparesis (i.e., weakness) } \\
2 \text { left-hemisphere hemiparesis (i.e., weakness) }\end{array}$ \\
\hline Aphasia etiology & 42 stroke, 1 other or unknown \\
\hline Types of aphasia & $\begin{array}{l}18 \text { Anomic } \\
12 \text { Broca's } \\
10 \text { Conduction } \\
0 \text { Global } \\
0 \text { Mixed Transcortical } \\
0 \text { Transcortical Motor } \\
1 \text { Transcortical Sensory } \\
1 \text { Wernicke's } \\
1 \text { Not Aphasic by WAB (i.e., scoring }>93.8 \text { on WAB) }\end{array}$ \\
\hline
\end{tabular}

WAB AQ = Western Aphasia Battery Aphasia Quotient

SLP $=$ speech-language pathology

*=as measured by Western Aphasia Battery Revised Aphasia Quotient, where $100=$ no aphasia

$\wedge=$ "gender" is the terminology used by AphasiaBank as of publication, but only two options were given to

respondents: male or female. This therefore may not reflect other genders (e.g., non-binary, transgender) reflected in the dataset. 
Table 4: Descriptive and comparative statistics for language and gesture variables divided by task. 43).

\begin{tabular}{|c|c|c|c|c|c|}
\hline \multirow{2}{*}{\begin{tabular}{|r|} 
Variable \\
Group \\
\end{tabular}} & \multicolumn{2}{|c|}{$\begin{array}{l}\text { Window Task } \\
\mathrm{M}(\mathrm{SD}, \text { range })\end{array}$} & \multicolumn{2}{|c|}{$\begin{array}{l}\text { Sandwich Task } \\
\mathrm{M}(\mathrm{SD} \text {, range })\end{array}$} & \multirow[t]{2}{*}{$\begin{array}{l}\text { Repeated measures statistics } \\
\text { By group }(\mathrm{N}=75 ; \mathrm{N}=43)\end{array}$} \\
\hline & $\mathrm{N}=75$ Whole & $\mathrm{N}=43$ Matched & $\mathrm{N}=75$ Whole & $\mathrm{N}=43$ Matched & \\
\hline Task duration (secs) & $54.51(37.33,10-228)$ & $59.67(31.18,10-135)$ & $44.96(29.00,5-140)$ & $45.86(25.49,5-111)$ & $\begin{array}{l}\mathrm{N}=75, \mathrm{Z}=-2.65, \mathrm{p}=.008 \\
\mathrm{~N}=43, \mathrm{Z}=-2.88, \mathrm{p}=.004^{*}\end{array}$ \\
\hline \multicolumn{6}{|l|}{ Language variables } \\
\hline Utterances & $8.81(4.71,2-27)$ & $10.21(4.83,3-27)$ & $7.56(4.25,2-19)$ & $8.37(4.02,2-19)$ & $\begin{array}{l}\mathrm{N}=75, \mathrm{Z}=-2.01, \mathrm{p}=.05 \\
\mathrm{~N}=43, \mathrm{Z}=-2.10, \mathrm{p}=.04\end{array}$ \\
\hline Words per minute & $65.37(39.82,12-194.12)$ & $\begin{array}{l}65.06(40.29,17.14- \\
194.12)\end{array}$ & $\begin{array}{l}62.90(39.15,13.17- \\
213.33)\end{array}$ & $63.24(31.82)$ & $\begin{array}{l}\mathrm{N}=75, \mathrm{Z}=-.75, \mathrm{p}=.46 \\
\mathrm{~N}=43, \mathrm{Z}=-.27, \mathrm{p}=.79\end{array}$ \\
\hline $\begin{array}{l}\text { Hesitations } \\
\text { (proportion of total } \\
\text { words) }^{\wedge}\end{array}$ & $.41(1.01,0-7)$ & $.24(.46,0-3)$ & $.23(.19,0-.97)$ & $.22(.18,0-.68)$ & $\begin{array}{l}\mathrm{N}=75, \mathrm{Z}=.69, \mathrm{p}=.49 \\
\mathrm{~N}=43, \mathrm{Z}=1.49, \mathrm{p}=.14\end{array}$ \\
\hline \multicolumn{6}{|c|}{ Iconic gesture variables } \\
\hline Frequency & $1.84(2.59,0-11)$ & $3.21(2.71,1-11)$ & $7.11(439,1-34)$ & $7.35(3.24,2-15)$ & $\begin{array}{l}\mathrm{N}=75, \mathrm{Z}=-7.04, \mathrm{p}<.001^{*} \\
\mathrm{~N}=43, \mathrm{Z}=4.98, \mathrm{p}<.001^{*}\end{array}$ \\
\hline Rate & $.03(.06,0-.27)$ & $.06(.06,0-.27)$ & $.16(.09, .03-.41)$ & $.15(.09, .04-.41)$ & $\begin{array}{l}\mathrm{N}=75, \mathrm{Z}=7.36, \mathrm{p}<.001^{*} \\
\mathrm{~N}=43, \mathrm{Z}=5.42, \mathrm{p}<.001^{*}\end{array}$ \\
\hline
\end{tabular}

$*=$ significant at $\mathrm{p}<.007$ (Bonferroni correction across 7 repeated measures) per group (whole, matched).

${ }^{\wedge}$ Hesitations can have a larger proportion than 1 when they occur at a greater rate than total words. Hesitations include filled and unfilled pauses of greater than three seconds, false starts, and fillers. 


\section{Figure Captions}

1076 Figure 1. Distribution of gesture frequency (A) and gesture rate $(B)$ on both tasks $(N=75)$. Data 1077 callouts indicate average, whilst each data point (and its relative intensity/shadow) indicate 1078 individual subject scores.

1079

1080 Figure 2. Pairwise comparisons of gesture rate by fluency group, during Window task (top) and

1081 Sandwich task (bottom), for subgroup of subjects who made at least one iconic gesture on both 1082 tasks $(\mathrm{N}=43)$.

1083 


\section{Learning Outcomes}

1084 1. The reader will synthesize major hypotheses related to gesture usage in aphasia and how 1085 they relate to performance on specific discourse tasks.

10862 2. The reader will understand the difference between iconic gesturing and other language-like 1087 gestures, and the relationship between iconic gestures and spoken language.

1088 3. The reader will identify that task-specific gesturing (in particular, iconic gesturing) occurs 1089 in both persons with and without aphasia. 